\title{
Atividades produtivas e contexto socioeconômico da cooperativa D'Irituia
}

\author{
Productive activities and socioeconomic context of the cooperative D'Irituia
}

\begin{abstract}
Resumo
Este artigo objetiva descrever a cooperativa D'Irituia no que diz respeito ao seu processo de produção e contexto socioeconômico. Para realizar a coleta de dados, 29 entrevistas foram validadas em uma amostra de 90,63\%. Os questionários foram aplicados nos meses de janeiro, fevereiro e março de 2019. Dentre as principais atividades produtivas desenvolvidas pelos cooperados, destacou-se a produção de produtos florestais não madeireiros. O sistema de produção desenvolvido está baseado em sistemas agroflorestais com predominância de espécies frutíferas. A boa participação das mulheres no quadro social é decisiva para o desenvolvimento da cooperativa, porém, a força de trabalho encontra-se diminuída. É imprescindível buscar certificação orgânica. Existe ainda, a necessidade de fortalecer cada vez mais a marca D'Irituia. Nesse sentido, é fundamental o apoio governamental para projetar os produtos da cooperativa, pois a não diferenciação das embalagens dificulta uma identidade visual que represente a cooperativa.
\end{abstract}

Palavras-chave: Certificação, produção orgânica, sistema agroflorestal.

\begin{abstract}
This article aims to describe the D'Irituia cooperative regarding its production process and socioeconomic context. To perform data collection, 29 interviews were validated in a sample of 90.63\%. The questionnaires were applied in January, February and March 2019. Among the main productive activities developed by the members, the production of non-timber forest products stood out. The production system developed is based on agroforestry systems with predominance of fruit species. The good participation of women in the social framework is decisive for the development of the cooperative, but the workforce is diminished. It is essential to seek organic certification. There is also the need to increasingly strengthen the D'Irituia brand. In this sense, governmental support to design the cooperative's products is fundamental, since the non-differentiation of the packaging hinders a visual identity that represents the cooperative.
\end{abstract}

Keywords: Certification, organic production, agroforestry system.

Paula Francyneth Nascimento Silva ${ }^{\mathrm{I}}$, Cyntia Meireles Martins ${ }^{\mathrm{II}}$, Osvaldo Ryohei Kato ${ }^{\mathrm{III}}$, Marcia Athayde Moreira ${ }^{\mathrm{IV}}$, José Sebastião Romano Oliveira ${ }^{\mathrm{V}}$.

IUniversidade Federal Rural da Amazônia. Belém, PA. paulanascimento1414@gmail.com.

II Universidade Federal Rural da Amazônia. Belém, PA. cyntiamei@ hotmail.com.

IIIUniversidade Federal Rural da Amazônia. Belém, PA. osvaldokato@gmail.com.

${ }^{\mathrm{IV}}$ Universidade Federal Rural da Amazônia. Belém, PA. athayde.marcia@gmail.com.

VUniversidade Federal Rural da Amazônia. Belém, PA. zeromanoff@gmail.com. 


\section{Introdução}

O município de Irituia encontra-se localizado em uma região que começou a ser ocupada ainda no século XVIII, quando as comunidades rurais surgiram de atividades ligadas aos rios e igarapés, surgindo dessa forma, uma forma de colonização baseada no trabalho familiar que tinha como principal sistema de uso da terra, a prática da derruba e queima da vegetação para limpeza e preparo da área para o cultivo da mandioca, matéria-prima utilizada para produção de farinha d'água, principal produto gerador de renda e subsistência das famílias rurais na região.

Essa prática de limpeza de área foi amplamente utilizada em Irituia, onde o cultivo de mandioca (Manihot esculenta) para produção de farinha foi a atividade mais antiga praticada pelos agricultores familiares do município até meados da década de 1980 (OLIVEIRA, 2006). Nesse período, devido à prática constante da atividade, pode-se dizer que a produção de farinha de mandioca teve seu auge na região. No entanto, devido ao empobrecimento do solo proveniente da alta frequência de trabalho na terra e do preparo de derruba e queima, esta atividade foi entrando em crise e aos poucos sendo substituída por outras formas de cultivo.

Uma dessas formas foi a diversificação da produção por meio do avanço dos quintais agroflorestais para outras unidades da propriedade desses agricultores, que ao perceberem a decadência da produção de mandioca em suas unidades produtivas, resolveram expandir seus quintais para outras áreas da propriedade. Vale frisar que esta atividade já coexistia com o plantio de mandioca, porém, a destinação dos produtos dos quintais era para a sobrevivência e segurança alimentar da família.

Segundo Oliveira (2006), através da extensão dos sítios para áreas que se encontravam em pousio, como roças e áreas de monocultivos que inicialmente não contaram com intervenção, os agricultores criaram arranjos produtivos, modificando as paisagens das suas unidades de produção familiares. Certamente, isso levou a um processo de transição muito importante no município, com o abandono do monocultivo de mandioca, para uma forma mais diversificada de cultivo.

Essa modificação ocorreu devido a percepção dos agricultores de poder aumentar a produção de alimentos oriundos dos quintais agroflorestais. Os agricultores não somente expandiram a área plantada, mas também diversificaram ainda mais suas unidades de produção com espécies frutíferas e florestais. Muitas espécies encontradas nos sistemas de produção não eram cultivadas, mas já faziam parte dos quintais agroflorestais presentes nas unidades de produção.

Diante disso, em parceria com instituições governamentais e não governamentais, a produção agroflorestal em Irituia passou a ter mais atenção, de forma que o município foi incluído no Programa de Desenvolvimento Socioambiental da Produção Familiar Rural na Amazônia (PROAMBIENTE); uma das políticas públicas do Governo Federal que objetivou compatibilizar a conservação ambiental com o processo de desenvolvimento rural (LIMA et al., 2013).

A partir dos incentivos feitos pelo PROAMBIENTE Pólo Rio Capim, como a remuneração de serviços ambientais para compensar a cobertura dos custos de oportunidades para mudanças qualitativas de uso da terra, focando em sistemas de produção identificados com as especificidades de cada bioma (OLIVEIRA, 2006) foi evidenciado o papel das agroflorestas em Irituia, que contribuíram para a preservação ambiental, uma vez que ao reduzir o uso do fogo, característico da agricultura itinerante, para a utilização de um sistema mais complexo e mais estável, houve a implantação dos Sistemas Agroflorestais (SAFs) oriundos da expansão dos quintais (LIMA et al., 2013).

Por conta do avanço dos SAFs no município, o poder público por meio da Secretaria Municipal de Agricultura passou a dar apoio aos agricultores, de modo que a partir de 2009, estes foram incorporados no programa municipal que reconheceu a prática dos SAFs como um processo produtivo alternativo viável para agricultura familiar, que conciliava produção com conservação ambiental na região(KATO et al., 2012).

Nesse contexto, no que tange ao objeto de estudo, em 6 de abril de 2011, por meio da organização dos agricultores, houve a criação da Cooperativa Agropecuária dos Agricultores Familiares Irituenses (D'Irituia), objetivando-se ter acesso a mercados para comercializar a produção excedente oriunda dos SAFs. 
Sabe-se que a organização em cooperativa pode beneficiar os cooperados não apenas no que diz respeito ao processo de comercialização da produção, mas também na agregação de valor, prestação de serviços, garantias trabalhistas e assessoria técnica. Além de facilitar o acesso do agricultor às novas tecnologias e insumos que são necessários para a produção, as cooperativas ajudam a disseminar conhecimento para o melhor manejo das culturas, a reduzir os custos relativos à produção, processamento e distribuição. As cooperativas também podem ser usadas para neutralizar a concorrência imperfeita (poder de monopsônio/oligopólio) entre os compradores, criando um maior poder de barganha entre os agricultores (ILRI, 1995). Dessa maneira, este artigo objetiva descrever a cooperativa D'Irituia no que diz respeito ao seu processo de produção e contexto socioeconômico.

\title{
Referencial Teórico
}

\subsection{Histórico do município}

Historicamente, a cultura itinerante foi demasiadamente utilizada pelos agricultores familiares do município de Irituia, que têm no seu processo de habitação a explicação para a utilização desse sistema. De acordo com Hurtienne (1999):

\begin{abstract}
"Durante séculos, extrativistas tradicionais e agricultores itinerantes como os grupos indígenas, caboclos e ribeirinhos (e no nordeste do Pará, os paraenses) foram os grupos populacionais mais importantes na Amazônia rural [...]. Com a construção da ferrovia [...]estabelece-se um campesinato agrícola na Zona Bragantina com base numa agricultura itinerante de pousio já altamente orientada ao suprimento do mercado de Belém. Nos anos de 40 e 50 [...] esse processo de colonização estendeu-se à região Guajarina no Nordeste paraense (Capitão Poço e Irituia)" (p.76).
\end{abstract}

A Zona Guajarina apresenta uma colonização distinta das demais regiões do nordeste paraense, se caracteriza pela dinâmica "rio-várzea-floresta", sucedendo o processo de ocupação da região Bragantina e do Salgado, tendo sua colonização datada no século XVIII. Até a década de 1960, foi em torno dos rios que se organizou a vida das populações amazônicas, nas décadas de 1930 a 1950 a Zona Guajarina configurou-se como uma das áreas responsáveis pelo abastecimento de Belém, onde arroz (Oryza sativa) e farinha de mandioca representavam o excedente exportado para a capital. Assim, os grupos sociais que se formaram nesta sub-região, ainda no século XVIII, inseriram-se no processo estabelecido na Amazônia até a primeira metade do século XX, tendo no rio Guamá (antigamente chamado de Guajará), e seus afluentes, a gênese das primeiras vilas que originaram atuais municípios que abrangem a região (SOUSA; MACEDO 2015; CAÑETE, 2005).

Nesse contexto, por ter sua população composta principalmente por negros e ribeirinhos, o município sempre teve a agricultura como base de sua economia desde os primórdios de sua criação, do total de moradores presentes em Irituia, quase $80 \%$ encontram-se na zona rural e por essa razão a economia é baseada na agricultura e no extrativismo (SILVA et al., 2015). O produto interno bruto municipal é mantido pelos serviços industriais e agropecuários, seguido das indústrias e atividades agropecuárias (ALMEIDA; FERREIRA, 2015).

Para Costa (1997) no que se refere à implantação de culturas permanentes em Irituia, verificava-se que até a primeira metade da década de oitenta correu uma completa estagnação quanto ao plantio de perenes. Isto ocorreu, segundo o autor, porque as culturas permanentes foram utilizadas para compor os pomares caseiros (hoje denominados quintais agroflorestais, característicos da região), mantendo-se como dominante o sistema vigente do município por quase um século, que tinha na produção da farinha de mandioca para mercado, a sua principal atividade.

Além dessa produção de farinha, cita-se em Irituia o período áureo do tabaco (Nicotiana tabacum) e malva (Malva sylvestris), que predominaram por algum tempo como atividade geradora de renda que proporcionava segurança em produzir, pois conforme relata Oliveira (2006), o comércio era garantido para esses produtos. 
Alguns agricultores rurais ao perceberem que suas produções entraram em declínio ao longo dos anos, despertaram então, para a necessidade de mudar a sua forma de produção. Por meio de práticas com ações diversas, buscaram meios para sobreviver ou subsistir que não dependesse apenas do sistema tradicional de roça, mas que diversificasse sua produção e garantisse também a conservação do meio ambiente. Esses agricultores não se limitaram ao sistema de corte e queima e resolveram estender os tradicionais sítios para outras parcelas de suas unidades produtivas. Desenvolveram em suas propriedades, dessa forma, os sistemas agroflorestais, com uma conotação básica de autoconsumo (OLIVEIRA, 2006).

\subsection{Produção agroflorestal em Irituia}

Percebendo a possibilidade de aumentar a produção de alimentos oriundos dos quintais agroflorestais, as áreas de SAFs na lógica dos quintais foram expandidas em Irituia (OLIVEIRA, 2006). Miranda (2011) em sua pesquisa sobre a contribuição dos quintais agroflorestais para a segurança alimentar de agricultores familiares no baixo Irituia, observou que $60 \%$ dos agricultores familiares entrevistados possuíam quintais agroflorestais. Estes SAFs apresentavam potencial para serem realizadas atividades como apicultura e manejo da mata ciliar, entre outras.

Costa (1997) constatou que em Irituia se observava uma diversidade considerável de culturas permanentes, com concentração importante em cinco produtos principais - açaí (Euterpe oleracea Mart), caju (Anacardium occidentale L.), limão (Citrus spp.), laranja (Citrus spp.) e café -, que juntos perfizeram em torno de $86 \%$ da área. Entre estas, destacava-se com absoluta supremacia a área de açaí com $51 \%$ do total. O autor observou dois momentos importantes de formação de culturas permanentes no município: um que precedia 1970, representando 50\% de toda área em 1992, e outra recente, na segunda metade dos anos oitenta e nos primeiros anos dos anos noventa, períodos em que se implantou em torno de $35 \%$ do total da área com culturas permanentes.

Segundo o autor supracitado, até 1983 as culturas permanentes banana (Musa spp.), laranja, coco da Bahia (Cocos nucifera) e pimenta do reino (Piper nigrum), chegaram a representar $11,22 \%$ da área colhida total do município de Irituia, declinando a partir daí a participação das permanentes, até atingir 8,13\% no final da década (COSTA, 1997). Essa diminuição de implantação das permanentes em Irituia, nos anos 1980 segundo o autor, foi reflexo de uma relutância entre os agricultores em fazer mudanças significativas. Porém, os padrões reprodutivos dos camponeses de Irituia nos anos noventa, segundo o autor apresentou em termos percentuais $25 \%$ de culturas temporárias e $45 \%$ de permanentes.

Pode-se assim perceber que as condições estruturais do sistema, fizeram com que os agricultores mudassem as condições estruturais, pois ao implantarem os SAFs, compostos tanto por culturas permanentes quanto temporárias, proporcionaram uma contribuição importante quanto à maior segurança alimentar das famílias (OLIVEIRA, 2006).

No que diz respeito à segurança alimentar proporcionada pelos SAFs, Miranda (2011) relata que em Irituia os agricultores com quintais agroflorestais tiveram acesso a uma melhor condição nutricional ao consumirem maior quantidade e variedade de alimentos oriundos dos quintais, especialmente as frutas, ricas em vitaminais e sais minerais. Dados da pesquisa ressalta a importância dos quintais agroflorestais para introduzir variações na dieta alimentar, pois contribui na diversificação e complementação alimentar.

Com o objetivo de conhecer os sistemas produtivos dos agricultores filiados a Cooperativa D'Irituia, Silva et al. (2015) observaram que o sistema produtivo dos agricultores do município é bastante diversificado, as lavouras temporárias são formadas principalmente pelos cultivos de mandioca (Manihot esculenta), melancia (Citrullus lanatus), milho (Zea mays), abacaxi (Ananas comosus), feijão comum (Phaseolus vulgaris) e arroz comum (Oryza sativa). Enquanto as lavouras perenes são formadas geralmente pelas culturas de açaí, coco-da-baía, cupuaçu (Theobroma grandiflorum), pimenta-do-reino e cacau (Theobroma cacao). 


\subsection{Importância do cooperativismo para a agricultura familiar}

Com um mercado consumidor cada vez mais exigente e preocupado com a qualidade e origem dos produtos, a agricultura familiar enfrenta dificuldades em seu processo de comercialização. Vários fatores associados a isso podem causar essa realidade: falta de recursos para investir na produção, pequena escala produtiva, falta de transporte adequado para levar os produtos até o ponto de venda, desinformação das exigências de mercado, pouca instrução para ir em busca de melhores preços, carência de assistência técnica, entre outros.

A organização dos produtores por meio do cooperativismo da agricultura familiar, pode garantir mais competitividade aos produtos do campo, ampliando os mercados e facilitando o acesso às redes de comercialização, dando garantias ao consumidor da origem e qualidade dos produtos. Além disso, o cooperativismo configura-se também como importante canal de comercialização para os agricultores, representando o trabalho em conjunto e a busca por resultados positivos, o que pode configurar em produtos agrícolas de qualidade (VALENT et al., 2014).

Segundo Figari e Bialoskorski Neto (2015), o cooperativismo também auxilia na agregação de valor, uma vez que proporciona aos seus associados diversos serviços, agregando valor a eles por meio de assistência técnica, orientação, compra de insumos/produtos, fazendo, assim, render cada vez mais os recursos dos seus associados.

Nesse sentido, avaliando a relevância de uma cooperativa como alternativa de agregação de valor à produção familiar, Frank et al. (2014) observaram que a diversificação da produção agropecuária fortalece a agricultura familiar e que o processamento industrial agrega valor ao produto final. Também verificaram que $68,4 \%$ dos associados acreditam na garantia de mercado para sua produção através da cooperativa e que $26,3 \%$, acreditam que a união gera força para a aquisição de melhorias para fortalecer o negócio.

Souza et al. (2017) objetivando estudar sobre a certificação "Fair Trade" em cooperativas, especificamente na Cooperativa Agroextrativista Veneza do Marajó, observaram sobre as motivações para a comercialização em conjunto, que os cooperados destacaram os melhores preços na venda para a agroindústria e a possibilidade de alcance de novos mercados. Os autores concluíram que os cooperados têm mais confiança na comercialização coletiva e que a cooperativa vem tendo um crescimento expressivo na dimensão econômica, se diferenciando no mercado, principalmente, com a comercialização de produtos orgânicos que são valorizados tanto no mercado nacional quanto no internacional, o que foi percebido no aumento de renda da maioria dos cooperados.

Desta forma, percebe-se que o cooperativismo se configura como uma forte ferramenta para o fortalecimento da agricultura familiar, não apenas por atuar na orientação de mercado a seus agricultores, mas também por proporcionar a "liberdade" dos agricultores familiares da exploração que sofriam por parte dos atravessadores que lhes compravam a produção por valores exorbitantemente baixos. Assim sendo, é possível perceber a importância que o cooperativismo tem para com a agricultura familiar e o desenvolvimento rural sustentável.

\section{Material e métodos}

Este trabalho de pesquisa assumiu um caráter exploratório-descritivo, mesmo que se mantenha aberto à identificação e compreensão de novos fatores a partir de dados empíricos coletados. A pesquisa descritiva "expõe características de determinada população ou de determinado fenômeno. Pode também estabelecer correlações entre variáveis e definir sua natureza. Não tem compromisso em explicar os fenômenos que descreve, embora sirva de base para tal explicação" (VERGARA, 2004), de maneira, que os pesquisadores neste tipo de investigação têm preocupação prática, como acontece com a pesquisa exploratória (GIL, 2007). Assim, em resumo, pode-se dizer que a pesquisa é qualitativa, com um caráter exploratório-descritivo, e análises estatísticas superficiais. 


\section{1 Área de estudo}

A pesquisa foi realizada no município de Irituia, nordeste paraense, junto a 29 agricultores familiares do total de 32 cooperados ativos pertencentes à Cooperativa D'Irituia. De acordo com dados do Instituto Brasileiro de Geografia e Estatística (IBGE, 2016), a área territorial equivale a $1.379,362 \mathrm{~km}^{2}$ e a população estimada é de 31.673 habitantes, com densidade demográfica de 2,74 hab $/ \mathrm{km}^{2}$, sendo aproximadamente $19,1 \%$ residentes na zona urbana e $80,9 \%$ na zona rural.

A vegetação primitiva do município de Irituia era, predominantemente, a Floresta Densa dos baixos platôs. Com o advento da colonização da região Bragantina, ocorreram grandes desmatamentos que reduziram quase ao ponto de desaparecimento da cobertura florestal primitiva, dando ensejo ao surgimento da Floresta Secundária (FAPESPA, 2016). Nesse cenário destaca-se o papel dos SAFs, que têm mudado os arranjos produtivos locais, gerando recuperação ambiental por meio das agroflorestas.

\subsection{Constructos de avaliação}

Quanto aos aspectos socioeconômicos (Figura 1) foram consideradas as características da composição familiar (nível de instrução, faixa etária, sexo) e fontes de renda principais.

Para identificar se a forma de produção dos cooperados é diferenciada, foram levantadas informações sobre quais atividades desenvolvidas e de que forma ocorre a produção. Sendo assim, os dados de produção foram baseados em: "o quê"; "como", e "quando" é produzido? De modo que os dados coletados sobre a produção foram da safra 2018 (ano todo) e parte de 2019 (voltado apenas para o tucumã).

O conhecimento do conjunto das práticas de produção adotadas, aliado à percepção dos aspectos socioeconômicos, foram úteis para diagnosticar as especificidades do sistema dos agricultores agroecológicos de Irituia.

Figura 1 - Constructos de avaliação do contexto socioeconômico-produtivo da cooperativa D'Irituia.

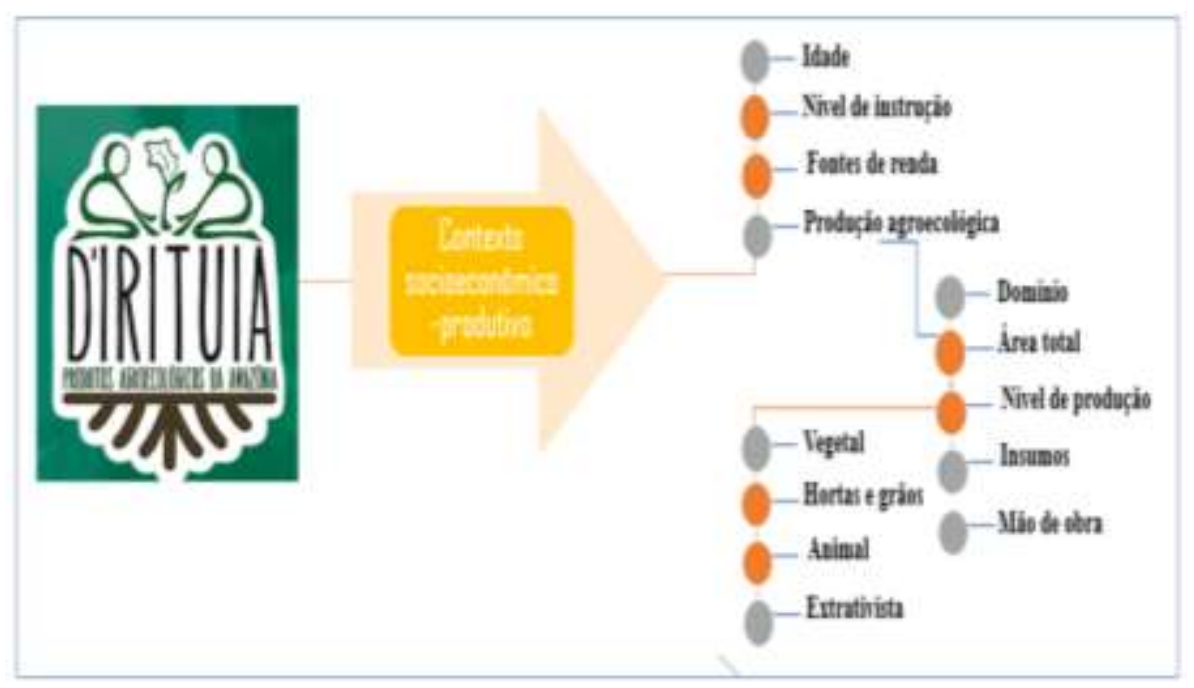

Fonte: Autores (2019). 


\subsection{Ferramentas para a coleta de dados}

Para realizar a coleta de dados, foram realizadas 29 entrevistas com os cooperados envolvidos diretamente na produção agroecológica. Por meio da aplicação de questionário, se obteve informações relativas ao contexto socioeconômico-produtivo desses agricultores. De modo que os questionários foram aplicados nos meses de janeiro, fevereiro e março de 2019.

Para a análise documental, o levantamento de dados foi realizado com a Diretoria da Cooperativa, onde foram levantados dados referentes ao histórico de fundação, parcerias, contexto atual, canais acessados. A entrevista em profundidade foi realizada por meio de roteiro semiestruturado, abordando aspectos referentes à gestão. Assim sendo, as ferramentas para a coleta de dados foram: análise documental, entrevista em profundidade com a Diretoria e aplicação dos questionários aos cooperados (Figura 2).

Figura 2 - Ferramentas para a obtenção de dados.

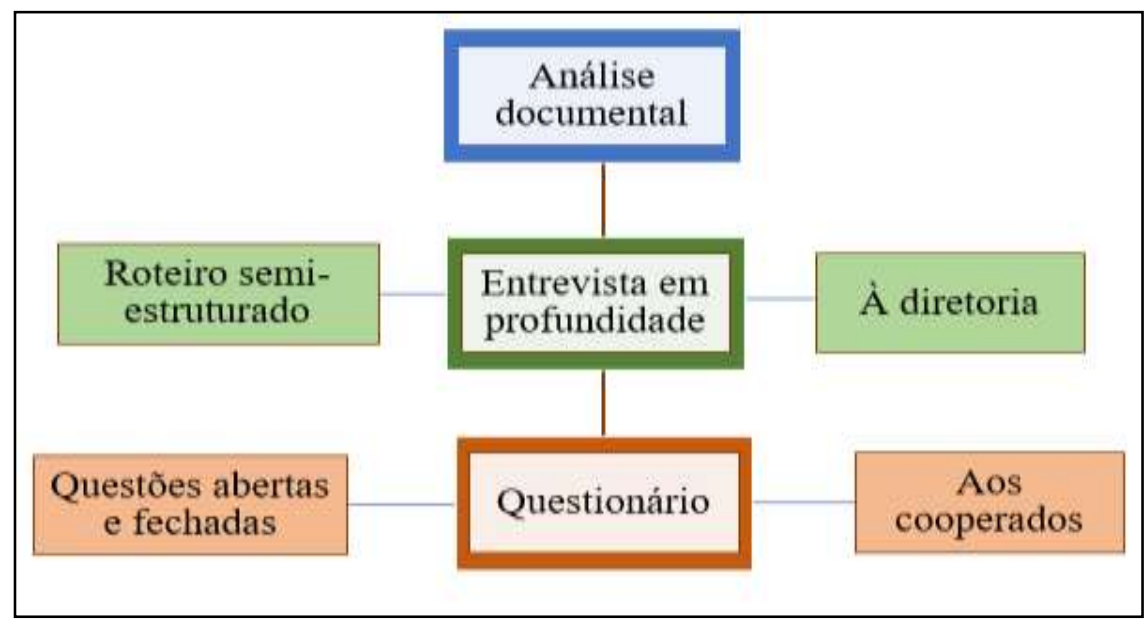

Fonte: A autores (2019).

\subsubsection{Análise documental}

Para a análise documental, considerou-se como documento todas as fontes de informação sobre a cooperativa que foram disponibilizados, tais como notas fiscais, recibos de venda, tabelas com dados de produção, dentre outros. Segundo Cechinel et al. (2016), a análise documental consiste em uma série de operações que visam estudar documentos que não receberam ainda um tratamento analítico, ou que ainda podem ser reelaborados de acordo com os objetos da pesquisa, no intuito de compreender circunstâncias sociais e econômicas.

\subsubsection{Questionário}

O questionário é um instrumento de investigação que visa recolher informações, geralmente mediante indagação à um grupo representativo da população em estudo. O questionário também é uma ferramenta importante porque proporciona a coleta de dados de um grande número de unidades produtivas em um espaço de tempo razoavelmente curto (WAGNER et al., 2010). Para tal, formulouse uma série de perguntas sobre o tema de interesse, sendo os principais itens abordados referentes ao perfil do agricultor, dados sobre a sua propriedade, práticas agrícolas adotadas entre outros.

Quanto aos tipos de questões, existem dois tipos: as de resposta aberta e as de resposta fechada. As questões de resposta aberta permitem ao inquirido construir a resposta com suas próprias palavras, facultando-lhe, deste modo, a liberdade de expressão. As questões de resposta fechada são aquelas nas quais o inquirido apenas seleciona uma opção ou várias dentre as apresentadas pelo 
pesquisador (WAGNER et al., 2010). Vale frisar que nesta pesquisa, os questionários foram elaborados com questões dos dois tipos (abertas e fechadas), o que o configura um questionário misto.

\subsubsection{Entrevista em profundidade}

O contexto da entrevista em profundidade pode ser considerado como um terreno "gerador de significados" que influencia diretamente na coleta de dados (MORÉ, 2015). Nesse sentido, a profundidade que se deseja está relacionada ao número de questões principais e complementares que se pretende abordar, visando analisar se as questões da entrevista em profundidade têm a potencialidade de gerar narrativas em torno do objetivo principal.

Diante disso, no contexto da investigação qualitativa, os participantes abordados pela entrevista foram os membros da diretoria, representados pelo: presidente, diretor de produção, e diretor comercial, além de um membro do conselho fiscal.

\subsubsection{Análise dos dados}

Foi construído um banco de dados em formato de planilha do programa Microsoft Office Excel 2010, e, posteriormente, realizou-se análises estatísticas superficiais, a partir da codificação por tabulação simples, distribuição de porcentagens, tabelas e figuras.

\section{Resultados e discussão}

\subsection{Perfil socioeconômico dos cooperados}

\subsubsection{Sexo e idade}

A cooperativa é formada por $58 \%$ de homens e $42 \%$ de mulheres. Apesar do número de homens ser maior, o número de sócias presentes no quadro demonstra uma boa participação das mulheres no quadro social da cooperativa, revelando uma organização que envolve o sexo feminino nas tomadas de decisão da D’Irituia.

Sendo assim, é possível inferir que essa presença das mulheres na cooperativa pode representar ganhos em termos de competitividade e produtividade, pois segundo Cielo et al. (2014), a maior participação e engajamento das mulheres nas distintas atividades agrícolas, tanto na produção quanto no gerenciamento, colabora para a geração de políticas públicas que permitam às mulheres se moverem ao longo da cadeia de valor, acessando mercados e contribuindo para o crescimento econômico.

A média de idade dos cooperados é de 52,93 anos, de modo que a faixa etária que apresenta maior frequência é a de idades entre 51 e 60 anos, totalizando 9 cooperados, seguidos pela segunda maior frequência que é encontrada na classe de 61 a 70 anos, com 7 cooperados. Essas duas classes representam $55,17 \%$ dos entrevistados, corroborando com os resultados encontrados por Souza et al. (2017) que ao estudarem a Cooperativa Agroextrativista Veneza do Marajó localizada em São Sebastião da Boa Vista/PA, também verificaram uma maior frequência de cooperados em idade acima dos 60 anos.

A força de trabalho já se encontra diminuída em termos de idade ativa laboral, pois o número significativo de entrevistados acima de 51 anos até 72 anos (62,07\%), representa perceptível transição da idade adulta para a idade avançada. Segundo Rambo (2016), números como os encontrados nesta pesquisa podem ser preocupantes, não apenas por conta do envelhecimento rural, mas também devido à baixa presença relativa de jovens no campo, fatores que se tornam motivo de preocupação quanto à capacidade de reprodução social do segmento da agricultura familiar.

Segundo Facioni e Pereira (2015), alguns motivos que levam os jovens a saírem do campo em busca de trabalho nos centros urbanos estão relacionados ao tamanho da área, a falta de mecanismos para aumentar a renda, o desfavorecimento da política agrícola e a busca de novos horizontes e tentativa de construírem suas vidas em outro local, comprometendo a sucessão familiar da empresa rural . Isto pode levar a uma crise 
de sucessão hereditária na agricultura familiar uma vez que não há herdeiros nas unidades produtivas que sucedam os pais (OLIVEIRA; SCHNEIDER, 2009). Sendo assim, a cooperativa D'Irituia deve auxiliar na formação de sucessores na propriedade, para atender tanto as necessidades econômicas como sociais dos jovens.

\subsubsection{Nível de escolaridade e renda}

Quanto à escolaridade identificou-se que a maioria dos cooperados possui ensino fundamental incompleto, representado $34,48 \%$ dos entrevistados. Os cooperados que estão ocupando essa predominância de baixo estudo, são na sua maior parte os de idade mais elevada. Essa realidade pode estar atrelada ao fato de que a maioria das escolas rurais da época desses agricultores, oferecia apenas o antigo primário (que ia da primeira até a quarta série do ensino básico).

Do total de cooperados, 27,59\% apresentam ensino médio completo e 20,69\% completaram nível superior, não havendo presença de analfabetos. A inexistência de analfabetismo, aliado ao fato de que a soma dos entrevistados que concluíram o nível fundamental, médio e superior é $65,52 \%$, significa maior qualificação das pessoas vinculadas à D'Irituia.

Essa realidade de instrução representa ganhos para a cooperativa no que diz respeito à orientação dos cooperados no processo produtivo, uma vez que aumenta a capacidade de atuação e de decisão dos indivíduos, possibilitando a obtenção de maiores rendas e melhor qualidade de vida (TARGANSKI et al., 2017). Além disso, um nível de instrução mais elevado, permite aos cooperados usarem de maneira mais adequada os insumos e equipamentos agrícolas, facilitando o acesso a inovações tecnológicas e informações, além do acesso a créditos, aumento do poder de negociação e acesso a mercados (ROSA et al., 2010).

Em relação ao percentual de cooperados com nível superior (20,69\%), vale destacar que 83,33\% destes são mulheres. Isto demonstra que as mulheres cooperadas possuem um bom índice de qualificação no que diz respeito ao nível de escolaridade. Nesse contexto, o atual perfil educacional das mulheres cooperadas, ressalta a importância da participação feminina para o crescimento e desenvolvimento da cooperativa.

\subsubsection{Fontes de renda}

Para a variável renda, constatou-se que $65,52 \%$ dos cooperados possuem renda agrícola e 34,48\% tem como fonte principal de renda atividades não agrícolas. Quanto à renda agrícola, os valores variam de $1 / 2$ salário mínimo até $\mathrm{R} \$ 1.500,00$. De modo que 52,63\% recebem um salário mínimo $(\mathrm{R} \$ 998,00)$ e 21,05\% tem renda de $\mathrm{R} \$ 1.500,00$. Esse percentual de cooperados com renda maior ocorre devido a maior produção de farinha, polpa e hortaliças realizada por eles. Vale ressaltar que os cooperados relataram que a renda agrícola varia bastante ao longo do ano em função da safra dos produtos comercializados, podendo ser maior ou menor que os valores informados.

Desta feita, é o possível observar que a agricultura se configura como a principal fonte de renda monetária dos produtores $(65,52 \%)$, apesar de que segundo os entrevistados, a renda obtida da produção agrícola dependendo da época do ano, pode ter um valor insuficiente para a manutenção financeira das famílias, sendo necessária a complementação através de programas assistenciais do governo. Hespanhol (2013) verificou que 63,2\% dos produtores entrevistados, possuía a agricultura como sua principal fonte de renda, corroborando com os dados verificados nesta pesquisa.

Quanto a renda não agrícola, os valores variaram em um salário mínimo (aposentadoria rural) e cinco salários mínimos (cooperado filho de agricultor, professor de nível superior).Rambo (2016) verificaram que somente $7,14 \%$ dos entrevistados recebiam mais de 2,01 salários mínimos/mês de renda de outra fonte. Esses resultados contrastam com os verificados nesta pesquisa, pois $40 \%$ dos entrevistados recebem valores acima de dois salários mínimos.

As fontes de renda não agrícola estão distribuídas em diversas atividades. $30 \%$ dos cooperados obtém renda do setor comerciário, divididos entre loja, lanchonete e farmácia. O mesmo percentual aparece para a soma do cargo de professor (30\%) que está disposto na rede municipal (10\%), estadual (10\%) e federal $(10 \%)$. 
Moraes e Sant'Ana (2015) verificaram em sua pesquisa que a faixa de renda bruta mensal de $64 \%$ das famílias era de até dois salários mínimos por mês e a principal fonte de renda apresentada foi o arrendamento, mas também as rendas resultantes de trabalho externo ao estabelecimento e a proveniente de aposentadorias/pensões eram importantes.

\subsection{Características da propriedade e da produção}

\subsubsection{Domínio Legal e Cadastro Ambiental Rural (CAR)}

Quanto ao domínio legal das propriedades, $73 \%$ dos cooperados detém a posse e o título da terra. Já no que diz respeito ao CAR, $61 \%$ dos cooperados declararam possuir o cadastro. Em termos de valor, isso pode ser um ponto de estrangulamento à captura de valor para produtores que não possuem as propriedades regularizadas, sendo uma questão que a cooperativa precisa atuar conjuntamente com as instituições responsáveis nessa regularização.

De acordo com Volpato et al. (2016), dentre as vantagens para os agricultores que possuem CAR vale destacar: a) o acesso ao crédito agrícola, com a possibilidade de obter financiamento agrícola com taxas de juros menores; b) o apoio do Poder Público por meio de ações de assistência técnica e extensão rural, produção e distribuição de sementes e mudas, e educação ambiental; e c) a possibilidade de conquista de certificações de produtos agrícolas ou florestais, garantindo maior competitividade de mercado, por assegurar o uso econômico de modo sustentável dos recursos naturais do imóvel rural.

\subsection{2 Área total da propriedade e área destinada a SAFs}

Com relação ao tamanho, as propriedades variaram de 0,3 a 74 hectares. Essa variação nos tamanhos de área total se dá por conta da presença lotes urbanos, três cooperados com área abaixo de 2 ha possuem quintais produtivos que estão localizados na cidade. O tamanho médio das propriedades pesquisadas é de 25,79 hectares (Tabela 2), revelando que a maioria das propriedades são minifúndios, ou seja, menores que o módulo fiscal do município que é de 55 hectares (INCRA, 2013).

O maior percentual $(31,03 \%)$ corresponde a propriedades com até 16 hectares, o que representa uma concentração de minifundiários, que teoricamente teriam pouco espaço para produzir. Apesar disso, como será discutido mais a frente, a diversidade de espécies encontrada nessas unidades, acaba tornando essas áreas altamente produtivas e sustentáveis.

Quando se analisa as maiores propriedades, os tamanhos variaram de 61 a 76 hectares, representando apenas $6,9 \%$ do total. Esse percentual corresponde às unidades de pequeno porte. Em termos de Brasil, a maioria dos imóveis rurais é de grande porte, porém, a realidade encontrada em Irituia revela a predominância da agricultura familiar no município.

Quanto a área destinada para SAFs (Tabela 1), verifica-se que 58,62\% são de 1 até 6 hectares, ressaltando a predominância de pequenas áreas. Esta realidade pode estar associada ao fato de que maioria dos SAFs presentes nos munícipios são oriunda da extensão dos quintais agroflorestais. Miranda et al. (2013) estudando a importância dos quintais agroflorestais aos agricultores familiares do Baixo Irituia, verificou que $60 \%$ dos entrevistados possuíam quintais agroflorestais e que estas unidades produtivas são uma alternativa de contribuição para a segurança alimentar.

Moraes (2017) verificou ao estudar a Cooperativa D'Irituia que houve ampliação dos quintais agroflorestais em todos estes agroecossistemas da pesquisa. A adoção de SAFs representou $16 \%$ da área cultivada, e desta área 5\% foi destinada aos quintais, enquanto o avanço do SAFs representou $11 \%$ da área cultivada. O avanço dos SAFs ocorreu em $60 \%$ das áreas dos agroecossistemas familiares, evidenciando a preferência por sistemas perenes diversificados, em detrimento aos sistemas simplificados. 
Tabela 1 - Tamanho de área destinada a SAFs dos agricultores familiares vinculados à cooperativa D'Irituia.

\begin{tabular}{c|c|c}
\hline Tamanho da área (ha) & Frequência absoluta & Frequência relativa (\%) \\
\hline Menor que 1 & 1 & 3,45 \\
\hline De 1 até 6 & 17 & 58,62 \\
\hline Maior que 6 até 11 & 4 & 13,79 \\
\hline Maior que 11 até 16 & 2 & 6,9 \\
\hline Maior que 16 até 21 & - & - \\
\hline Maior que 21 até 26 & 1 & 3,45 \\
\hline Não souberam informar & 4 & 13,79 \\
\hline Total & $\mathbf{2 9}$ & $\mathbf{1 0 0}$ \\
\hline
\end{tabular}

Fonte - Dados da pesquisa (2019).

\subsubsection{Declaração de produtor orgânico (DPO)}

Identificou-se que 22 cooperados $(75,86 \%)$ informou possuir Declaração de Produtor Orgânico, emitido pelo MAPA na categoria OCS (Organização de Controle Social), certificado que garante ao produtor fazer venda direta de produtos orgânicos aos consumidores. Porém, vale ressaltar que a cooperativa não possui certificação orgânica, portanto não dispõe, ainda, do selo de produção orgânica para comercializar seus produtos nessa categoria. Considerando que cerca de $1 / 3$ dos cooperados não possuem nem a declaração de produtor orgânico, tampouco a certificação orgânica, tem-se dificuldade em atestar produtos orgânicos para essa parte dos cooperados, o que pode prejudicar a captura de valor de todo o grupo.

De acordo com Moreira e Becker (2018), para que os agricultores possam acessar os principais canais de comercialização do mercado de orgânicos, é necessário que sejam submetidos a um processo de certificação. Carvalho Júnior e Hauffe (2013) estudando as motivações para a certificação na produção de alimentos orgânicos, constataram que a certificação proporciona maior confiança para o consumidor de que $o$ produto adquirido foi feito a partir do método orgânico, trazendo para a empresa maiores demanda e margem de lucro, portanto, conferindo valor aos produtos orgânicos.

\subsubsection{Produção Orgânica}

Quando perguntados sobre a situação da propriedade em relação a produção orgânica, $73 \%$ dos cooperados declararam que toda a propriedade está desenvolvendo forma de produção totalmente orgânica Já $17 \%$ dos cooperados afirmaram desenvolver produção paralela, ou seja, produz de forma orgânica e de forma convencional, e 10\% afirmam estar em transição.

Vale destacar que os cooperados consideram suas propriedades orgânicas por não utilizarem defensivos agrícolas e adubo químico na produção. Dentre as várias formas de adubos orgânicos utilizados podem ser citados a técnica de compostagem, casca de mandioca, esterco bovino e aviário, além da folhagem que é depositada no plantio.

Os SAFs desenvolvido pelos cooperados não estão livres de insetos e pragas, quando ocorre a incidência no sistema, 62\% declararam adotar o controle fitossanitário alternativo (Gráfico 1), com a aplicação de caldas preparadas a base de Nim indiano (Azadirachta indica), tabaco e tucupi. Essa mistura mantêm a população de inimigos naturais, está inteiramente livre de defensivos agrícolas e segundo relatado, são medidas de controle eficazes. Apesar disso, 7\% declarou usar de vez em quando algum tipo de inseticida químico, com a justificativa de que apenas o alternativo não é suficiente para fazer o controle, ou seja, essa prática por esse segmento dos respondentes retira valor do produto considerado como orgânico.

Ao serem perguntados sobre a limpeza de invasoras, $52 \%$ dos cooperados afirmou realizar capina manual (Gráfico 2). Já a roçagem mecânica é realizada por 38\% dos entrevistados, que utilizam a roçadeira como principal instrumento para esse tipo de limpeza, apenas um cooperado informou usar tratores.

Pompeu et al. (2009) estudando SAFs em áreas de agricultores familiares no município de Bragança, observaram que devido ao alto índice de invasoras nas áreas agrícolas cultivadas, 94\% dos agricultores 
faziam capina (manual, mecânica ou química) e aproximadamente $64 \%$ realizavam roçagem nas áreas de SAFs. Esses resultados corroboram com os dados verificados nesta pesquisa, pois também foi observado que houve predominância de capina no controle de invasoras.

Sabe-se que a infestação crescente de plantas invasoras nos sistemas agrícolas causa prejuízos à produção, porém, vale destacar que não foi identificado o uso de insumos químicos para a limpeza de área por nenhum dos entrevistados.

Gráfico 1 - Controle de pragas e doenças realizado pelos cooperados vinculados a D'Irituia.

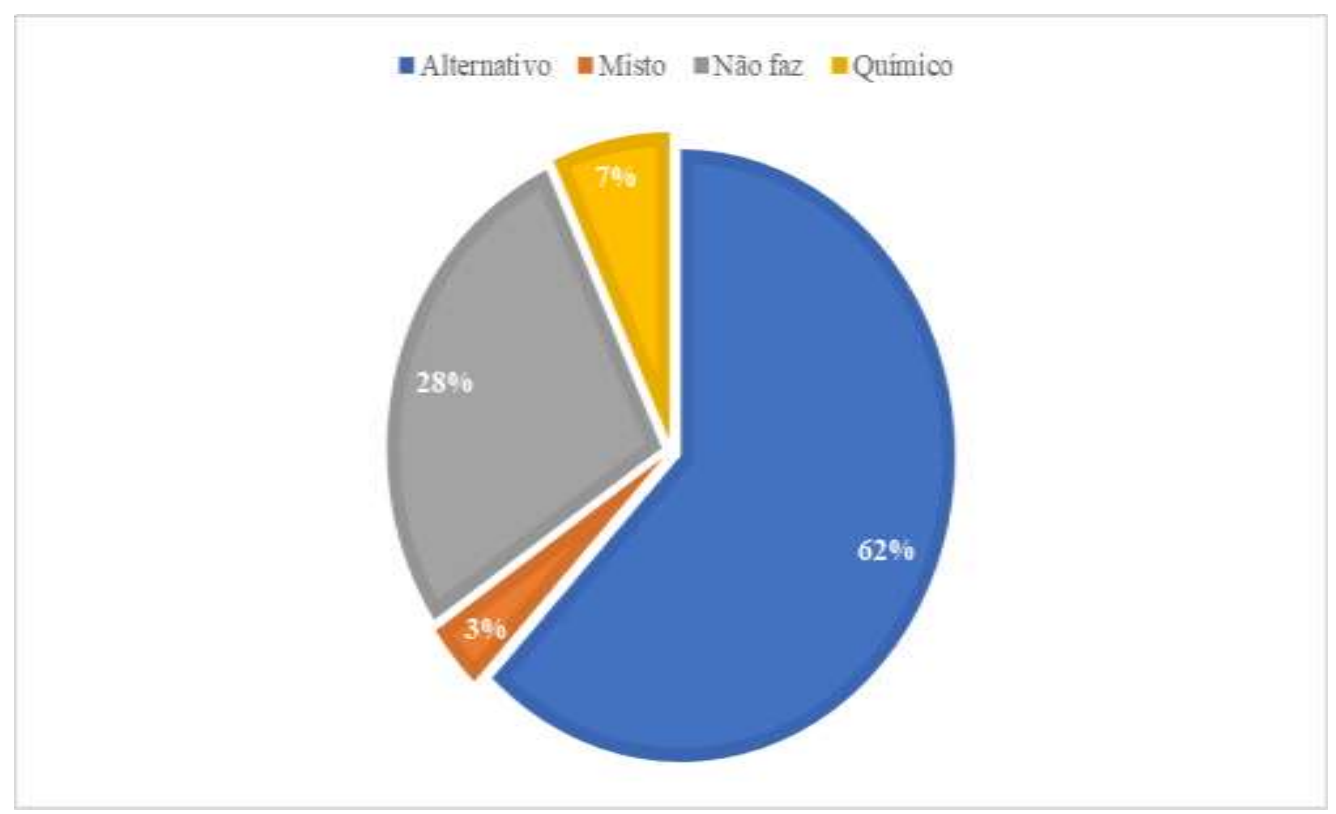

Gráfico 2 - Controle de invasoras realizado pelos cooperados vinculados a D'Irituia.

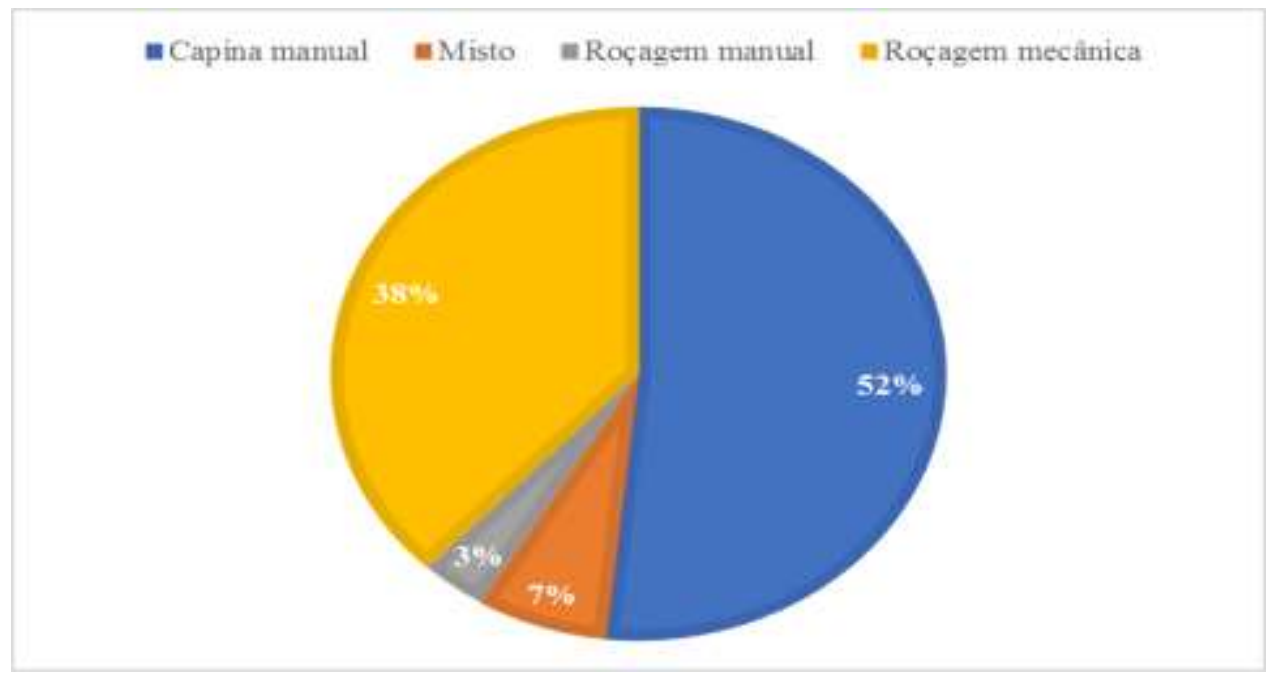

Fonte - Dados da pesquisa (2019).

Embora não haja emprego do preparo mecanizado com o uso de tratores e grades aradoras, é válido destacar o interesse dos agricultores familiares por esta forma de limpeza e preparo da terra, porém a falta de acesso a recursos financeiros para investimentos acaba sendo uma barreira para que os cooperados possam adquirir esses implementos.

Quanto ao uso da mão de obra familiar, há o complemento de pessoas contratadas para o trabalho nos estabelecimentos, o que demonstra predominância (66\%) do uso de mão de obra externa quando comparado ao trabalho totalmente familiar. A contratação de mão de obra externa ocorre como complemento à mão de obra familiar para o processamento de mandioca. A produção de farinha é uma das práticas mais 
antigas realizadas pelos agricultores familiares de Irituia, fato que pôde ser constatado nesta pesquisa onde se verificou que $44,83 \%$ desenvolvem a atividade em suas propriedades.

Sousa e Piraux (2015) verificaram em sua pesquisa uma recorrente necessidade de contratação de mão de obra para o processamento de mandioca, principalmente para as etapas de descasque e prensagem. Já no que diz respeito a Irituia, os cooperados informaram que a mão de obra contratada geralmente ocorre para a fase de torragem da farinha, etapa considerada por eles como a que demanda de maior esforço físico.

No que tange ao acompanhamento técnico, citou-se a carência de assistência técnica como um dos principais problemas relatados pelos cooperados quanto a produção, sendo que $76 \%$ declararam não ter acesso a nenhum acompanhamento técnico, nem mesmo de órgãos responsáveis pela assistência. Quando arguidos sobre como faziam para obter ajuda, a informação recebida foi de que além da própria experiência do agricultor, um parceiro (esposo de uma cooperada) que é técnico agrícola e dispõe de formação acadêmica e profissional, disponibiliza troca de informações para auxiliar os cooperados em suas dúvidas. Assim, o conhecimento técnico muitas vezes é realizado de maneira empírica e feito de forma aprendendo fazendo (learning by doing) com carência de inovação e orientação técnica, certamente comprometendo a captura de valor.

A dificuldade e a insatisfação dos agricultores em relação à assistência técnica recebida faz parte de um cenário nacional em que a ausência de prestação de serviços de assistência técnica e extensão rural (ATER), acaba sendo a realidade da maioria dos agricultores familiares. Gomes et al. (2017) estudando o acesso à ATER e os principais problemas técnicos enfrentados pela agricultura familiar no Nordeste Paraense, constataram que 70,8\% dos agricultores não recebem ATER, e comparativamente a Região de Integração na qual os agricultores familiares mais recebem assistência técnica, é a Região do Capim (42,5\%), região cujo município de Irituia está inserido.

Dessa feita, tem-se dificuldade em obter financiamento para as propriedades investirem e custearem suas produções. Portanto, a pesquisa apontou que o valor disponível para investir na produção foi um dos principais problemas relatados pelos cooperados, que interfere diretamente na falta de investimentos e custeio nas propriedades. Verificou-se neste estudo que $76 \%$ dos cooperados dispõem apenas de recursos próprios para desenvolver a atividade produtiva, $17 \%$ possuem empréstimo bancário e $7 \%$ foram beneficiados pelo crédito cidadão. O crédito cidadão é um programa de microcrédito do Governo do Estado do Pará, para criação e crescimento de pequenos empreendimentos no estado.

Sabe-se que o crédito para realizar investimento na produção, é um elemento essencial para que o agricultor possa produzir e comercializar seus produtos, especialmente os pequenos, o que compromete a captura de valor pelos cooperados. A ausência de recursos financeiros para investimentos na produção também foi verificada por Padovan et al. (2017). Os resultados em sua pesquisa revelaram que $32 \%$ dos agricultores relataram a falta de recursos financeiros para investir como uma das principais dificuldades enfrentadas na produção. Entretanto, comparado aos dados encontrados nesta pesquisa (76\%), percebe-se que os cooperados da D'Irituia demandam, urgentemente, de medidas a serem adotadas para o fortalecimento da produção.

Ademais, as condições das estradas para circulação da produção é outro ponto que dificulta o processo produtivo. Apesar de $76 \%$ dos cooperados possuírem transporte próprio (Gráfico 3), o tipo predominante são as motocicletas, e conforme relatado, principalmente no período chuvoso, é praticamente inviável transportar a produção até o ponto de venda. Isso ocorre porque devido às fortes chuvas, as estradas ficam esburacadas e lisas, tornando o transporte perigoso e arriscado.

Além disso, há de se considerar que o volume transportado em motocicletas é pequeno e muitas vezes esse tipo de transporte torna-se inadequado quanto ao tipo de produto que está sendo transportado. Gomes et al. (2019) estudando a logística empregada pelos agricultores familiares no fornecimento de alimentos para o Programa Nacional de Alimentação Escolar (PNAE), também verificaram problemas, principalmente, em relação ao tipo de transporte utilizado, observando inadequação no transporte de alimentos perecíveis. 
Gráfico 3 - Tipo de transporte para circulação da produção dos cooperados vinculados à cooperativa D'Irituia.

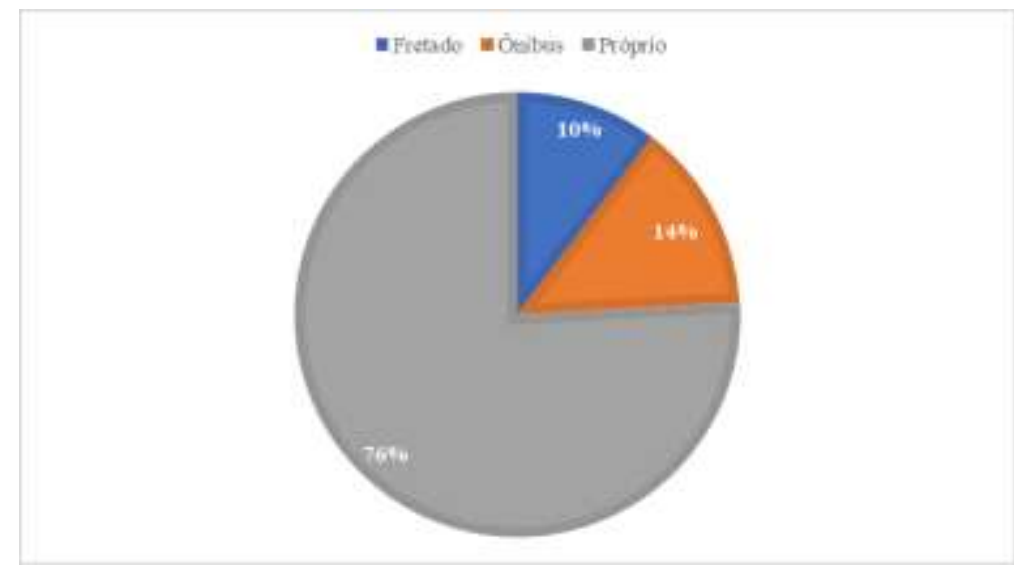

Fonte - Dados da pesquisa (2019).

\subsection{Histórico de organização da Cooperativa}

A cooperativa surgiu como resposta às necessidades dos produtores familiares de Irituia, que a muito tempo dependiam quase que, exclusivamente, de políticas estaduais e municipais para desenvolver seu processo produtivo e comercial.

Em 2009, a Secretaria Municipal de Agricultura de Irituia (SEMAGRI) passou a apoiar os agricultores que praticavam SAFs no município. No mês de março de 2009, houve a realização do "I Seminário Agropecuário de Irituia" coordenado pela SEMAGRI, momento em que surgiu a essência do movimento cooperativista no município de Irituia. Por meio de um grupo de agricultores que decidiu se organizar e com apoio de várias entidades, tais como Serviço Nacional de Aprendizagem Rural (SENAR), Serviço Brasileiro de Apoio às Micro e Pequenas Empresas (Sebrae), Empresa Brasileira de Pesquisa Agropecuária (Embrapa), Empresa de Assistência Técnica e Extensão Rural (Emater), Prefeitura de Irituia e, principalmente, a Organização das Cooperativas do Brasil (OCB) e Serviço Nacional de Aprendizagem do Cooperativismo (SESCOOP/ PA), se começou a estruturar o cooperativismo em Irituia (COOPERATIVA D'IRITUIA, 2018).

A proposta discutida no I Seminário, posteriormente, foi discutida e aprovada no Conselho Municipal de Desenvolvimento Rural Sustentável. Destas discussões surgiram ações concretas, entre estas a participação de agricultores na Feira de Produtos Orgânicos de Belém, o Fest Feira na sede municipal, e a comercialização direta com a prefeitura para compra da merenda escolar (KATO et al., 2012).

Em março de 2010 foi realizado o "II Seminário Agropecuário de Irituia", sendo encaminhada a realização do levantamento da produção local pela SEMAGRI para incentivar e fomentar a agricultura familiar do município de Irituia com base nos SAFs. Na oportunidade foram cadastradas 201 famílias para participar do programa da SEMAGRI. Assim, no ano de 2010/2011 foram distribuídos 65 mil mudas de espécies frutíferas e florestais, além de 56 mil sacos para produção de mudas pelos agricultores (KATO et al., 2012).

Motivados com a possibilidade de comercialização de sua produção, no ano de 2010, um grupo de agricultores locais decidiu se organizar e começou a planejar a formação de uma Instituição com o intuito de lançar seus produtos no mercado interno e externo ao município, visando o aumento de sua renda familiar (COOPERATIVA D'IRITUIA, 2018). Além das oportunidades de viagem técnica para Cooperativa Agrícola Mista de Tomé Açu e aos Sistemas Agroflorestais desse município, visitou-se o Centro de Treinamento Agroecológico Inovação Tecnologia e Pesquisa Aplicada do Nordeste Paraense; a Unidade Didática de Bragança (UDB) da EMATER; Feira da agricultura Familiar no Hangar (AGRIFAL); Feira do Empreendedor; Fazenda MALUNGA em Brasília; e $9^{\circ}$ Expor BRASIL no Rio de Janeiro (COOPERATIVA D'IRITUIA, 2018). 
Dessa maneira, a cooperativa surgiu como uma força de ligação comercial que poderia acessar mercados para os cooperados. Sendo assim, a D'IRITUIA é uma sociedade de natureza civil e sem fins lucrativos, constituída no dia 06 de abril de 2011, que se rege pelos valores e princípios do cooperativismo, pelas disposições legais, em sincronismo com o Programa de Autogestão e por seu Estatuto (COOPERATIVA D'IRITUIA, 2018).

De acordo com seu estatuto, a cooperativa tem como objetivo prestar serviços aos cooperados, congregando agricultores e pecuaristas de sua área de ação, realizando o interesse econômico dos produtores, mediante as seguintes atividades:

- Receber, cultivar, extrair, transportar, classificar, padronizar, armazenar, beneficiar, industrializar e comercializar a produção de seus cooperados registrando suas marcas se for o caso. (Aqui tem-se a possibilidade de agregar valor aos produtos por meio de marca, origem da produção como orgânica e proveniente da agricultura familiar, o que pode oportunizar melhores preços aos produtores, pelo posicionamento diferenciado dos mesmos no mercado).

- Adquirir ou colocar à disposição dos seus cooperados, na medida em que o interesse socioeconômico aconselhar, bens de produção e insumos tais como: sementes, mudas, fertilizantes de origem orgânica, corretivos agrícolas, produtos veterinários, alimentos para animais, máquinas e equipamentos agrícolas se for o caso, combustíveis, biodiesel, produtos e gêneros de uso doméstico e pessoal necessários ao desenvolvimento de suas atividades. (Vale frisar que esta possibilidade poderia facilitar o fomento ao acesso às inovações, sendo a cooperativa elemento impulsionador de práticas e inovações sustentáveis).

- Prestar assistência tecnológica ao quadro social, em estreita colaboração com órgãos públicos e terceirizados atuantes no setor. (Este objetivo poderia solucionar a carência orientação técnica dos cooperados, visto que $76 \%$ declararam não ter acesso a nenhum acompanhamento técnico, nem mesmo de órgãos oficiais responsáveis pela assistência. A força da cooperativa por meio do estabelecimento de parcerias efetivas poderia dirimir tal problemática).

- Fazer, quando possível, adiantamento em dinheiro sobre o valor dos produtos recebidos dos cooperados ou que ainda estejam em fase de produção transformada. (Considerando que $76 \%$ dos cooperados dispõem apenas de recursos próprios para desenvolver a atividade produtiva, o adiantamento financeiro aos cooperados facilitaria o custeio da produção, oportunizando maior valor tanto ao produto quanto à própria cooperativa).

- Obter recursos para o financiamento de custeio da produção e realização de investimentos dos cooperados. (Note-se conforme análise realizada no tópico anterior, quanto ao domínio legal das propriedades, apenas $61 \%$ dos cooperados declararam possuir o Cadastro Ambiental Rural, sendo esse um requisito ao acesso às fontes oficiais de financiamento).

- Promover com recursos próprios ou convênios, a capacitação cooperativista e profissional do seu quadro social, funcional, técnico, executivo e diretivo da Cooperativa. (A capacitação constante dos cooperados e da cooperativa é condição sine qua non à construção de valor e, portanto, melhor desempenho tanto ambiental, quanto produtivo, social e financeiro, além de colaborar para melhor auto-gestão e governança cooperativa).

- Prestar outros serviços relacionados com a atividade econômica da Cooperativa e/ou seus cooperados.

- Trabalhar para o desenvolvimento sustentável da sua comunidade, mediante políticas aprovadas pelos seus membros.

- Desenvolver economicamente a produção nas segmentações agropecuárias para: fruticultura regional, horticultura, pecuária, caprinocultura, piscicultura, aquicultura, aves, reflorestamento, SAFs (Sistemas Agroflorestais), extrativismo, plantas medicinais, apicultura, minhocultura e floricultura. (Neste item tem-se como um dos objetivos da cooperativa fomentar a diversificação produtiva dos cooperados, indo ao encontro da produção orgânica por meio de Sistemas Agroflorestais). 
- Colocar à disposição dos cooperados e de seus familiares, no que couber, o serviço de assistência técnico agronômico, veterinário, educacional, jurídico, de saúde e social, bem como, aos funcionários da cooperativa, valendo-se para isso de parte dos recursos dos fundos de Reserva de Assistência Técnica e Educacional e Reserva Legal (RATES).

- Colocar à disposição dos cooperados, diretamente ou mediante a interveniência de terceiros contratados, os serviços de assistência para elaboração de planos, projetos técnicos e de fiscalização, bem como, de pesquisas e treinamentos que visem o aprimoramento tecnológico da atividade objeto da empresa.

- Potencializar as propriedades dos cooperados para a atividade econômica via turismo rural ou ecológico, proporcionando aos seus familiares e às demais pessoas da comunidade oportunidades de negócios como, guia, artesanatos. (Foi verificado que alguns cooperados já desenvolvem essa atividade, recebendo visitas de várias instituições. Isso demostra que a cooperativa visa explorar outras potencialidades do rural, fomentando a pluriatividade entre os cooperados, ou seja, tanto atividades agropecuárias e florestais quanto não agrícolas).

O princípio da cooperativa foi de que "governos passam, mas os agricultores continuam agricultores" e somente a organização pode possibilitar novos caminhos, entre eles a comercialização e o acesso aos mercados que sempre foi o "gargalo" dos agricultores.

\subsubsection{Contextualização atual da cooperativa}

Atualmente, a cooperativa é composta por 32 cooperados, cuja organização social fez ressurgir entre os cooperados a antiga prática esquecida no tempo e que muito tinha valor: o mutirão. Esta prática tem sido utilizada no plantio de sistemas produtivos agroecológicos como os SAFs e na limpeza da área comprada para implantação do futuro complexo agroindustrial: casa de extração de oleaginosas, casa de farinha mecanizada e casa de polpa de frutas (COOPERATIVA D'IRITUIA, 2018).Vale frisar que esse é um ponto importante para captura de valor aos produtos da cooperativa, pois, como ainda não se dispõe de agroindústria para o beneficiamento de sua produção, grande parte do processamento dos produtos ainda é feito pelos próprios cooperados antes da entrega na cooperativa.

Na figura 5 tem-se a primeira logo da cooperativa que, em 2015, foi trocada indicando maior vínculo de seus produtos à forma de produção (orgânica) e origem (cooperativa de agricultores familiares). Note-se que uma das formas de posicionar o produto de forma diferenciada é através da construção e valor das marcas, o que conforme Araújo et al. (2008) está estritamente relacionada aos objetivos organizacionais e a implementação de estratégias de negócio, sendo que os consumidores a consideram como uma parte importante do produto, já que, o nome da marca e o que ele representa são um importante ativo. Para os autores, ao estudarem a marca "vinho do porto", identificaram um posicionamento natural e único, possuindo nome diferenciado e a identificação imediata do produto pelo consumidor (ARAÚJO et al., 2008). Assim, a evolução da marca dos produtos da cooperativa D'Irituia, certamente, visa criar valor ao produto, pelo seu melhor posicionamento (Figura 3).

Outro ponto importante, principalmente no ramo alimentício, é o da escolha e formatação adequada do rótulo e embalagem, ainda conforme estudo de Araújo et al. (2008). Para os autores, além de identificar o produto ou a marca, pode também classificar o produto ou descrever várias coisas sobre ele, como por exemplo, o produtor, o local e data de produção, a medida, e a data de validade. No estudo do Vinho do Porto, citaram o uso de imagens contidas nas garrafas que representarem navios, rosas dos ventos, a Cruz de Malta, ou seja, imagens que remetam ao passado português da época das navegações ou propriamente à história do vinho (ARAÚJO et al., 2008). 
Figura 3 - Evolução do logo da cooperativa D'Irituia. (A) Primeira logo da cooperativa D'Irituia; (B) Nova logo da cooperativa D'Irituia.
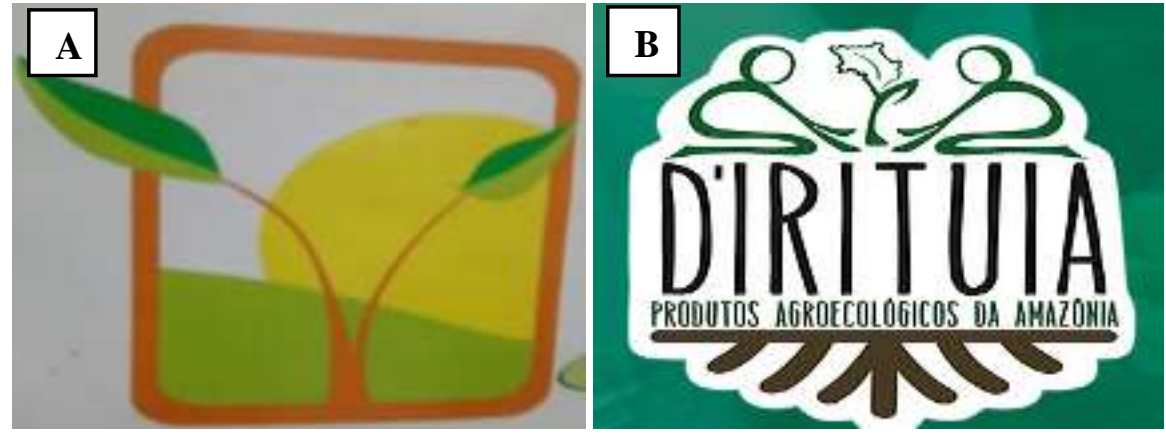

Fonte: Dados da pesquisa (2019).

No caso da cooperativa D'Irituia, ainda não há um design para embalagem que diferencie os vários tipos de produtos gerados pela cooperativa, no caso das polpas (Figura 4), foi produzida uma embalagem comum a todas as polpas. Mas, atualmente, essa embalagem já não existe mais, por estar ocorrendo o desenvolvimento do modelo adequado a cada tipo de polpa.

Figura 4 - Embalagem de polpa usada pela cooperativa D'Irituia.
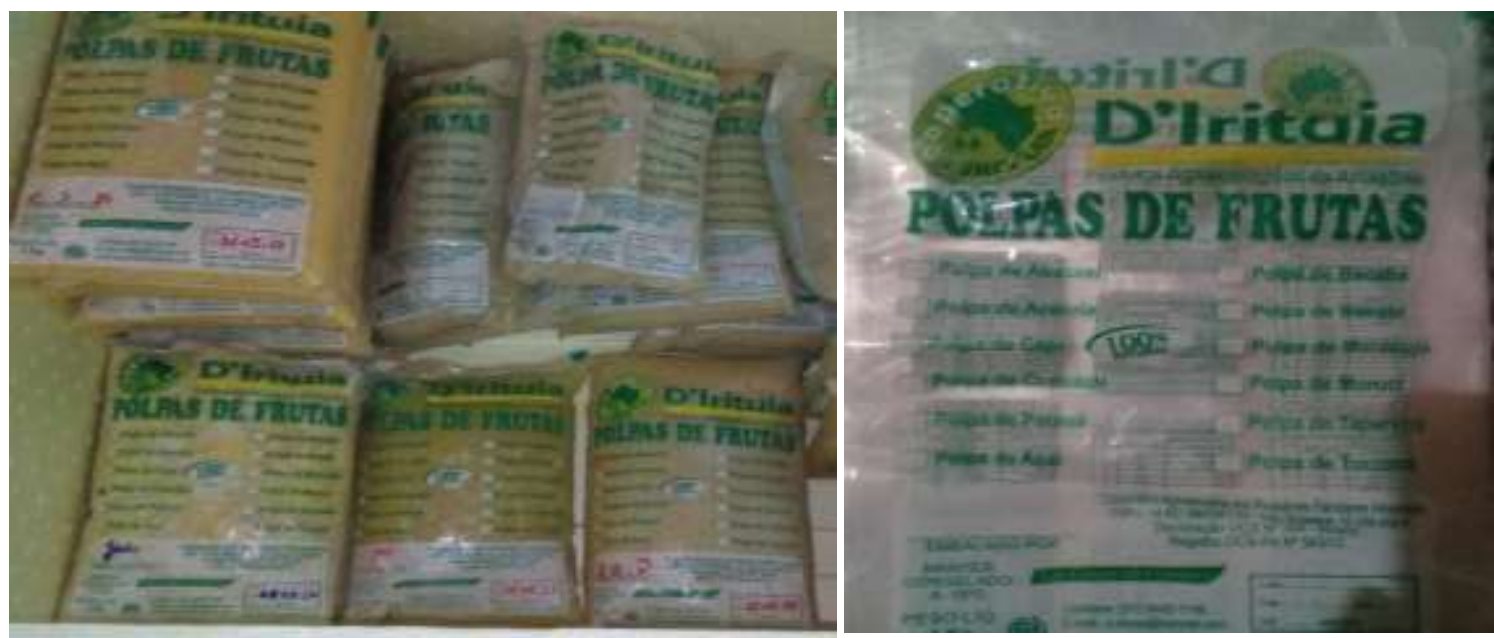

Fonte - Dados da pesquisa (2019).

Vale frisar, que a busca pela identificação dos elementos de identidade, auxilia a competitividade e a entrada dos produtos em novos mercados, haja vista que o design melhora a qualidade aparente dos produtos (embalagem/rotulagem) e cria uma apresentação que estabelece um vínculo entre o produto e seu consumidor, conferindo vantagem competitiva e uma interação bemsucedida (MERINO et al., 2007).

Assim sendo, face a essa dificuldade enfrentada pela cooperativa na diferenciação de seus produtos, será feita uma reorganização das embalagens que, atualmente, ainda são comuns a todas as polpas transacionadas pela cooperativa, sem diferenciação para cada tipo de polpa (Figura 6). Esse problema, aliado à falta de Selos de Inspeção Estadual e Federal (SIE e SIF), impedem que a cooperativa comercialize seus produtos dentro e até mesmo fora do município, pois não há rotulagem nem selos. Por isso, a cooperativa D'Irituia, atualmente, conta com o apoio do Serviço de Apoio à Micro e Pequenas Empresas (Sebrae) para apoiá-la no desenvolvimento dos rótulos e embalagens para os produtos apresentados (Quadro 1). 
Quadro 1 - Rótulos e embalagens a serem desenvolvidos pelo Sebrae para os produtos solicitados pela cooperativa.

\begin{tabular}{c|c}
\hline Produto & Tamanho da embalagem \\
\hline $\begin{array}{c}\text { Polpa de frutas (caju, maracujá, muruci, abacaxi, } \\
\text { acerola, goiaba, cupuaçu, açaí e cacau) }\end{array}$ & $1 \mathrm{Kg}$ \\
\hline Farinha d'água e de tapioca & $1 \mathrm{Kg}$ e $500 \mathrm{~g}$ \\
\hline $\begin{array}{c}\text { Cachaça de jambu } \\
\text { Licor (maracujá, cupuaçu, açaí, jambu, murici e } \\
\text { jenipapo }\end{array}$ & 1 litro \\
\hline Brigadeiro caseiro & 1 litro \\
\hline Mandioqueijo & Caixa com 10 unidades \\
\hline
\end{tabular}

Fonte: Dados da pesquisa (2019).

Ressalta-se que todas as rotulagens que necessitarem de registro deverão obedecer às normas técnicas de rotulagem da Agência de Defesa Agropecuária do Estado do Pará (ADEPARÁ), para o produto artesanal ou órgão fiscalizador competente.

Sobre a organização da sua base produtiva, ao longo de seus oito anos de fundação, a cooperativa tem avançado na sua organização, desenvolvendo diferentes sistemas de produção e cadeias produtivas. Porém, o grande gargalo dos cooperados tem sido a comercialização e a agregação de valor para alcançar melhores preços, considerando que, são os próprios produtores que fazem essa transformação do produto antes da sua entrega na cooperativa.

\subsubsection{Atores sociais e organizações parceiras importantes na construção dos mercados da cooperativa}

Desde o início de sua formação, a cooperativa contou com o apoio de outras organizações além dos cooperados fundadores. Dessa forma, a organização deve sua evolução às parcerias estabelecidas e a determinados atores sociais fundamentais nesse processo (nesse caso como atores sociais citam-se os sócios fundadores) que acreditaram na cooperação como uma possibilidade de melhorar de vida e obter renda através da venda de seus produtos.

No entanto, torna-se necessário ressaltar que os trabalhos da cooperativa desde a sua fundação foram e ainda estão sendo desenvolvidos por meio de parcerias estabelecidas que têm se ampliado ao longo dos anos. No âmbito local destacam-se a Paróquia Nossa Senhora da Piedade e o Sindicato dos trabalhadores e trabalhadoras rurais de Irituia, ambos com parceria na utilização de espaços para eventos e reuniões da cooperativa.

Em um âmbito de maior alcance está a parceria com o Sistema OCB/SESCOOP que disponibilizou todo o suporte técnico na formação e fundação da cooperativa e ainda hoje oferece capacitação contínua sobre cooperativismo e comercialização. Além deste, cita-se o Instituto de Desenvolvimento Florestal e da Biodiversidade (Ideflor) que possibilitou capacitação de alguns cooperados por meio do Projeto Tijolo Verde.

Além dos parceiros já citados, as entidades de pesquisa devem ser mencionadas porque atuam diretamente na capacitação dos cooperados, deve-se destacar o papel da Empresa Brasileira de Pesquisa Agropecuária (EMBRAPA) com capacitação na pesquisa participativa em sistemas agroflorestais; a Universidade Federal Rural da Amazônia (UFRA-campus Belém e Capitão-poço), Universidade Federal do Pará (UFPA-campus Belém) bem como Instituto Federal do Pará (IFPAcampus Castanhal) com capacitação dos cooperados e filhos dos cooperados através de realização de 
cursos, minicursos e palestras, além de pesquisas de TCC, mestrado e doutorado sendo realizadas na cooperativa; e a Incubadora Tecnológica (INCUBATEC) parceira na capacitação dos filhos de cooperados, assistência técnica e auxílio na implantação de projetos. Esse tipo de parceria promove a capacitação dos cooperados e traz possibilidades inovadoras em termos de produção e processos de gestão (SOUZA; SOBRINHO 2011).

Outros parceiros relevantes são a Empresa de Assistência Técnica e Extensão Rural do Estado do Pará com capacitação e assistência técnica com emissões de Declaração de Aptidão ao PRONAF (DAP) individuais e jurídica; a Agência de Defesa Agropecuária do Estado do Pará que auxilia na implantação de projetos; o Serviço de Apoio à Micro e Pequena Empresa que tem apoiado no sentido de orientar os cooperados na rotulagem, código de barras e outros.

Além destes, destaca-se a parceria com a Cooperativa Agrícola Mista de Tomé-Açu, o intercâmbio com essa cooperativa que é referência no Nordeste Paraense, possibilitou troca de informações e treinamento aos cooperados, que puderam implantar em suas propriedades os SAFs com a experiência de quem já desenvolvia a atividade a muito mais tempo no município de Tomé Açu, um dos municípios pioneiros na implantação de SAFs na região. Para que haja um desenvolvimento e fortalecimento do cooperativismo é importante que exista esse tipo de intercâmbio de informação entre cooperativas, trocas de experiências, produtos e serviços que viabilizam o setor como atividade econômica.

Nesse contexto, de acordo com Souza e Sobrinho (2011) a consolidação de parcerias entre instituições governamentais e entidades civis, organizações não governamentais, igrejas, universidades, institutos de pesquisa, centrais sindicais, dentre outros, são necessários para o avanço e fortalecimento das cooperativas. Desta feita, essa consolidação de parcerias é condição primordial como estratégia de integração das cooperativas no que diz respeito à participação em redes de colaboração para atendimento de demandas específicas, na qual todas as entidades se apoiam umas na outras, cada uma com sua função, fortalecendo-se mutuamente (SOUZA; SOBRINHO, 2011). Estas parcerias podem promover a resolução de pontos de estrangulamento que impedem maior valor aos produtos D'Irituia.

\subsection{Atividades produtivas desenvolvidas pelos cooperados e agregação de valor à produção}

\subsubsection{Atividades de produção}

Dentre as principais atividades produtivas desenvolvidas pelos cooperados, destacou-se a produção de produtos florestais não madeireiros com $79 \%$ dos cooperados envolvidos na atividade (Gráfico 4). Os produtos florestais não madeireiros encontrados foram: andiroba (Carapa guianensis), ucúuba (Virola surinamensis), murumuru (Astrocaryum murumuru), tucumã (Astrocaryum aculeatum), e mel de abelha. Esse maior percentual verificado para essa categoria, ocorreu por conta da produção de tucumã que ocorre no período de dezembro (2018) a abril (2019). Porém, vale ressaltar que essa produção ocorre em um único período do ano, não sendo, portanto, a principal atividade desenvolvida pelos cooperados.

Nesse sentido, já que a produção de polpas ocorre o ano todo, pode-se considerar essa atividade como a principal, uma vez que, mensalmente, $66 \%$ dos cooperados transformam frutas em polpas. A produção de frutas in natura, ocupa $55 \%$ dos cooperados sendo a matéria prima utilizada para a produção de doces, geleias, licores, e polpas, sendo esta última, a principal forma de agregação de valor citada pelos entrevistados, realizada de forma individual e não cooperada. 
Gráfico 4 - Percentual de cooperados em relação às principais atividades produtivas desenvolvidas pelos cooperados vinculados a D'Irituia.

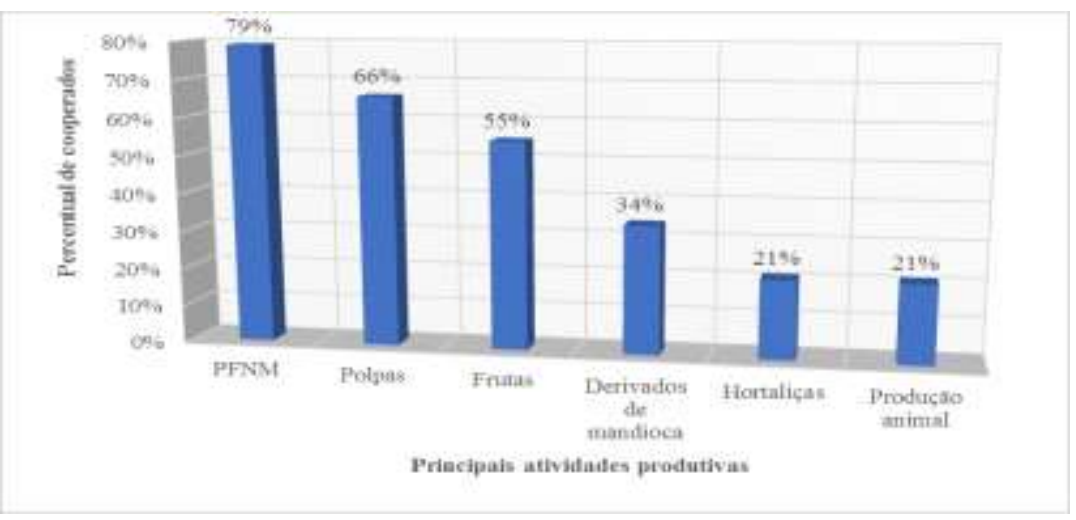

Fonte - Dados da pesquisa (2019).

A quantidade produzida de frutas in natura equivale a $83.240 \mathrm{~kg}$ (Tabela 3). As três principais são: laranja, açaí e abacaxi. A produção de laranja, apesar de ocupar o primeiro lugar com 48,05\% do total geral, apresenta apenas $6,9 \%$ dos cooperados envolvidos na atividade. Isso se justifica pelo fato de que apenas dois produtores desenvolvem o monocultivo de laranja, o que demostra que esses cooperados são exceção quando comparados a maioria dos agricultores que produzem em forma de SAFs.

Já o açaí, mesmo ocupando a segunda posição com $21,31 \%$ de toda a produção (Tabela 4), apresenta 27,59\% dos cooperados desenvolvendo a atividade. Esse mesmo percentual de produtores envolvidos $(27,59 \%)$ foi verificado para a produção de abacaxi, que apresenta $12,88 \%$ do total. Chama-se atenção para o percentual de açaí, que faz parte dos SAFs, sendo dividido em produção nativa e plantada.

Tabela 4 - Produção de frutas in natura, frequência de produtores que desenvolvem a atividade e quantidade total produzida no ano 2018 , dos cooperados vinculados a cooperativa D'Irituia.

\begin{tabular}{l|c|c|c|c|c|}
\hline $\begin{array}{c}\text { Frutas } \text { in } \\
\text { natura }\end{array}$ & Nome científico & $\begin{array}{c}\text { Frequência de } \\
\text { produtores que } \\
\text { desenvolvem a } \\
\text { atividade* }\end{array}$ & \%** & $\begin{array}{c}\text { Quantidad } \\
\text { e total (kg) }\end{array}$ & \%** \\
\hline Laranja & Citrus spp. & 2 & 6,90 & 40.000 & 48,05 \\
\hline Açaí & Euterpe oleracea & 8 & 27,59 & 17.740 & 21,31 \\
\hline Abacaxi & Ananas comosus & 8 & 27,59 & 10.725 & 12,88 \\
\hline Melancia & Citrullus lanatus & 2 & 6,90 & 9.000 & 10,81 \\
\hline Limão & Citrus spp. & 3 & 10,34 & 2.900 & 3,48 \\
\hline Pupunha & Bactris gasipaes & 4 & 13,79 & 2465 & 2,96 \\
\hline Manga & Mangifera indica & 1 & 3,45 & 210 & 0,25 \\
\hline Cupuaçu & Theoobroma & 1 & & 200 & 0,24 \\
\hline Tangerina & Citrundiflorum reticulata & 1 & 3,45 & - & - \\
\hline Total geral & & - & - & $\mathbf{8 3 . 2 4 0}$ & - \\
\hline Coco verde & Cocos nucifera & 1 & - & 200 & - \\
\hline
\end{tabular}

Fonte - Dados da pesquisa (2019).

* O entrevistado pôde assinalar mais de uma alternativa. ** O percentual foi calculado com base nos 29 entrevistados. *** O percentual foi calculado com base nos $83.240 \mathrm{~kg}$.

O total de produção de polpas foi de $7.801 \mathrm{~kg}$ (Tabela 5). As três principais polpas produzidas foram a de abacaxi, muruci (Byrsonima crassifolia) e cupuaçu. A predominância da produção de polpa de abacaxi representa $25,64 \%$ da produção total, o que representa $2.000 \mathrm{~kg}$ produzidos por 
17,24\% dos cooperados. Apesar da produção de polpa de cupuaçu ocupar o terceiro lugar, observa-se na tabela 3 que essa atividade é que a tem maior frequência de cooperados realizando a atividade, representando 37, 93\% do total geral. Isto ressalta que o cupuaçu é uma das principais espécies que compõem os SAFs dos cooperados e, portanto, prevalece como uma das frutas de maior interesse, tanto econômico como ecológico.

A produção de polpa de caju (Anacardium occidentale) e graviola (Annona muricata) apresentaram as menores produções, sendo 6,79 e $0,36 \%$, respectivamente. Essa baixa produção ocorre devido ao menor número de cooperados envolvidos nessa atividade. Isso pode ser justificado pelo fato de que, segundo os entrevistados, essas polpas têm pouco interesse no mercado regional, no caso do caju precisa-se considerar que há uma grande disponibilidade do suco na forma industrializada nos supermercados, o que poderia justificar a baixa produção pelos cooperados.

Tabela 1 - Produção de polpas, frequência de produtores que desenvolvem a atividade e quantidade total produzida no ano 2018 , dos cooperados vinculados a cooperativa D'Irituia.

\begin{tabular}{l|c|c|c|c}
\hline Produção de polpas * & $\begin{array}{c}\text { Frequência de produtores } \\
\text { que desenvolvem a } \\
\text { atividade }\end{array}$ & \%** & $\begin{array}{c}\text { Quantidade } \\
\text { total (kg) }\end{array}$ & \%*** \\
\hline Polpa de abacaxi & 5 & 17,24 & 2000 & 25,64 \\
\hline Polpa de muruci & 3 & 10,34 & 1212 & 15,54 \\
\hline Polpa de cupuaçu & 11 & 37,93 & 1187 & 15,22 \\
\hline Polpa de acerola & 8 & 27,59 & 904 & 11,59 \\
\hline Polpa de taperebá & 3 & 10,34 & 800 & 10,26 \\
\hline Polpa de maracujá & 6 & 20,7 & 580 & 7,43 \\
\hline Polpa de açaí & 5 & 17,24 & 560 & 7,18 \\
\hline Polpa de caju & 2 & 6,9 & 530 & 6,79 \\
\hline Polpa de graviola & 1 & 3,45 & 28 & 0,36 \\
\hline Total geral & - & - & $\mathbf{7 . 8 0 1}$ & - \\
\hline
\end{tabular}

Fonte - Dados da pesquisa (2019).

* O entrevistado pôde assinalar mais de uma alternativa. ** O percentual foi calculado com base nos 29 entrevistados. $* * * \mathrm{O}$ percentual foi calculado com base nos $7.801 \mathrm{~kg}$.

Dessa feita, os resultados apresentados nas tabelas 4 e 5 revelam que o sistema de produção desenvolvido pelos cooperados está baseado em SAFs com predominância de espécies frutíferas, que geram produtos a serem comercializados tanto na forma processada (polpas) como frutas in natura. Com base nesses dados, constatou-se que os $66 \%$ dos agricultores que agregam valor à produção, ao realizarem o beneficiamento de frutas oriundas dos SAFs, desenvolvem esse processo, predominantemente, de forma artesanal e em conjunto com as atividades domésticas.

No que diz respeito à transformação da mandioca, diferente das polpas, já há um padrão na embalagem desse produto. Seus derivados representam um total de $14.030 \mathrm{~kg}$ (Tabela 6). De modo que a produção de farinha (não foi diferenciado se d'água, seca, ou etc.) prevaleceu como a principal atividade de transformação da mandioca, sendo realizada por $27,50 \%$ dos cooperados, o que corresponde a $95,58 \%$ da quantidade total produzida. Desta feita, pode-se afirmar que a mandioca é a cultura mais cultivada pelos produtores cooperados da Cooperativa D'Irituia, haja vista a predominância de seus subprodutos em relação as demais categorias. 
Tabela 2 - Produção derivados de mandioca, frequência de produtores que desenvolvem a atividade e quantidade total produzida no ano 2018 , dos cooperados vinculados a cooperativa D'Irituia.

\begin{tabular}{l|c|c|c|c}
\hline Derivados de mandioca* & $\begin{array}{c}\text { Frequência de produtores } \\
\text { que desenvolvem a } \\
\text { atividade }\end{array}$ & $\mathbf{\% *}$ & $\begin{array}{c}\text { Quantidade total } \\
(\mathbf{k g})\end{array}$ & $\mathbf{\%} * * *$ \\
\hline Farinha de mandioca & 8 & 27,59 & 13.410 & 95,58 \\
\hline Farinha de tapioca & 3 & 10,34 & 250 & 1,78 \\
\hline Folha de maniva cozida & 1 & 3,45 & 50 & 0,36 \\
\hline Goma & 4 & 13,79 & 270 & 1,92 \\
\hline Macaxeira ralada & 1 & 3,45 & 50 & 0,36 \\
\hline Total geral & - & - & $\mathbf{1 4 . 0 3 0}$ & - \\
\hline Tucupi & 3 & 10,34 & 100 litros & - \\
\hline
\end{tabular}

Fonte - Dados da pesquisa (2019).

* O entrevistado pôde assinalar mais de uma alternativa. ** O percentual foi calculado com base nos 29 entrevistados. $* * * \mathrm{O}$ percentual foi calculado com base nos $14.130 \mathrm{~kg}$.

Vale destacar que o processamento de farinha realizado por alguns cooperados sofreu modificações ao longo dos anos para ser um produto diferenciado no mercado. A qualidade visual da farinha, aliada ao sabor e crocância do produto são fatores decisivos na hora da compra, por isso, através de cursos realizados e também da experiência pessoal, esses cooperados passaram a desenvolver etapas diferenciadas para gerar uma farinha "especial" que se destacasse na hora da venda.

Segundo um entrevistado pioneiro dessa diferenciação declarou, "o segredo para uma boa farinha está na fase de torra". Essa etapa é a última do processamento e ocorre depois que a mandioca já foi descascada, triturada, prensada e peneirada. Nessa fase, ocorre o escaldamento (a massa peneirada vai úmida para o forno) e é mexida manualmente até que comece a torrar, conforme relatado "nessa fase não se pode perder o tempo, nem mais nem menos".

Vale ressaltar que esse processo de produção da farinha de mandioca não é desenvolvido por todos os cooperados, apenas cerca de $10 \%$ adota essa forma de diferenciação, que foi desenvolvida por meio da parceria com a UFRA (Capitão Poço) que seguindo as normas do MAPA, estabeleceu os procedimentos necessários para uma produção diferenciada. $\mathrm{O}$ restante dos produtores ainda segue a forma tradicional de processamento. A farinha diferenciada é classificada em três subgrupos de granulometria: tipo 1 (granulometria fina, geralmente usada para farofa); tipo 2 (granulometria média) e tipo 3 (granulometria grossa). A farinha convencional, na época da pesquisa estava custando em média $\mathrm{R} \$ 1,50 \mathrm{~kg}$, enquanto a diferenciada (tipo 2) custava $\mathrm{R} \$ 3,35 \mathrm{~kg}$. Percebe-se, dessa feita, uma agregação de valor de $123,33 \%$ quando se comparam os preços da farinha convencional em relação a farinha diferenciada.

A produção de horta gerou um total de $4.405 \mathrm{~kg}$ (Tabela 7), os três principais são o jambu, couve e cheiro verde, juntos somam $91,15 \%$ de toda a quantidade produzida e envolvem $20,69 \%$ de cooperados na produção. O jambu desponta como o principal produto, totalizando $75,26 \%$ de toda a produção hortícola, o que equivale a $3.315 \mathrm{~kg}$.

A maior produção de jambu pode estar atrelada ao amplo uso desta planta na culinária paraense. Homma et al. (2011) afirmam que o jambu é uma hortaliça amazônica que geralmente tem sua produção intensificada de acordo com um calendário de eventos, que começa com o Carnaval, Semana Santa, Dia das Mães, São João, Dia dos Pais, Círio de Nazaré, Natal e Ano Novo. Segundo esses autores, um produtor de jambu tradicional que mora em municípios próximos a Belém, destina metade dos canteiros para a época das festividades do Círio de Nazaré e 1/4 para o período normal (HOMMA et al., 2011). 
Em Irituia não é diferente, o jambu faz parte da gastronomia cultural do município, com maior intensidade de produção próxima a datas festivas como o festival da cultura irituense que ocorre em julho e o círio de Nossa Senhora da Piedade que se realiza em outubro. Apesar disso, o consumo de jambu pode ser diário na mesa da população que o utiliza para a elaboração de pratos do dia a dia, como cozido de carne, salada crua, além dos tradicionais pratos pato no tucupi e tacacá.

A produção de grãos totalizou $2.980 \mathrm{~kg}$ (Tabela 7), o milho apesar de ocupar a primeira posição com $16,25 \%$ do total geral, é uma atividade que envolve apenas 3,35\% dos cooperados. Já a produção de café e milho, envolvem juntas $13,8 \%$ dos cooperados, somando $22,75 \%$ de toda a quantidade produzida.

A produção animal é desenvolvida por poucos cooperados, os quais produzem peixe, galinha caipira e porco. O tambaqui (Colossoma macropomum) lidera a produção em quilos (455 $\mathrm{kg}$ ) representando $79,13 \%$ da quantidade total $\mathrm{em} \mathrm{kg}$.

Tabela 7 - Produção de horta e grãos, frequência de produtores que desenvolvem a atividade e quantidade total produzida no ano 2018 , dos cooperados vinculados a cooperativa D'Irituia.

\begin{tabular}{c|c|c|c|c}
\hline Produto* & $\begin{array}{c}\text { Frequência de } \\
\text { produtores que } \\
\text { desenvolvem a atividade }\end{array}$ & $\begin{array}{c}\% \\
* * *\end{array}$ & $\begin{array}{c}\text { Quantidade } \\
\text { total (kg) }\end{array}$ & $\begin{array}{c}\% \\
* * * *\end{array}$ \\
\hline \multicolumn{4}{|c|}{ Horta } \\
\hline Jambu (Acmella oleracea) & 6 & 20,69 & 3315 & 75,26 \\
\hline Couve (Brassica oleracea) & 6 & 20,69 & 360 & 8,17 \\
\hline $\begin{array}{c}\text { Cheiro verde (Petroselinum } \\
\text { crispum) }\end{array}$ & 6 & 20,69 & 340 & 7,72 \\
\hline Cariru (Amaranthus viridis) & 1 & 3,45 & 200 & 4,54 \\
\hline Pimentinha (Capsicum spp) & 1 & 3,45 & 100 & 2,27 \\
\hline $\begin{array}{c}\text { Tomate cereja (Solanum } \\
\text { lycopersicum var. cerasiforme) }\end{array}$ & 1 & 3,45 & 50 & 1,14 \\
\hline Alface (Lactuca sativa) & 1 & 3,45 & 40 & 0,91 \\
\hline Total & - & - & 4.405 & - \\
\hline Milho (Zea mays) & Grãos & 3,45 & 1200 & 40,27 \\
\hline Feijão (Phaseolus spp) & 1 & 6,90 & 900 & 30,20 \\
\hline Café (Coffea spp.) & 2 & 6,90 & 780 & 26,17 \\
\hline Feijão branco (Phaseolus spp) & 1 & 3,45 & 100 & 3,36 \\
\hline Total & - & - & $\mathbf{2 . 9 8 0}$ & - \\
\hline
\end{tabular}

Fonte - Dados da pesquisa (2019).

* O entrevistado pôde assinalar mais de uma alternativa. ** O percentual foi calculado com base nos 29 entrevistados. $* * * \mathrm{O}$ percentual foi calculado com base nos $4.405 \mathrm{~kg}$.**** O percentual foi calculado com base nos $2.980 \mathrm{~kg}$.

\section{Considerações finais}

Constatou-se que a boa participação das mulheres no quadro social é decisiva para o desenvolvimento da cooperativa, porém, destaca-se que a força de trabalho se encontra diminuída em função da maior presença de cooperados em idade avançada. Desta feita sugere-se o desenvolvimento de novas pesquisas voltadas à inserção do público jovem no quadro de sócios da cooperativa, somente assim será possível garantir a continuidade da organização, bem como das atividades relacionadas à agricultura familiar. 
Se torna imprescindível buscar certificação orgânica, isto trará benefícios inigualáveis para a cooperativa, uma vez que o certificado de conformidade traz para os consumidores uma maior credibilidade no modo como os alimentos foram produzidos. Além disso, a cooperativa necessita atuar na regularização ambiental dos através de parcerias com instituições responsáveis pelo cadastramento ambiental rural, pois isto certamente irá colaborar positivamente para a agregação de valor.

Dessa maneira, a cooperativa desenvolve boas atividades produtivas, entretanto, é necessário atuar na padronização das embalagens e na valorização dos produtos diferenciados, tal como a farinha de mandioca, estabelecendo e fortalecendo cada vez mais a marca D'Irituia para que se possa ter um maior reconhecimento da produção agroecológica realizada pela organização. Nesse sentido, é fundamental o apoio governamental para projetar os produtos da cooperativa, pois, a não diferenciação das embalagens dificulta uma identidade visual que represente a cooperativa, atestando a questão da identificação de origem, especificamente neste caso, o produtor e os aspectos geográficos marcantes, evidenciando e resgatando os valores oriundos da agricultura familiar.

\section{Referências}

ALMEIDA, B. J. X. de; FERREIRA, C. P. (2015). Mapeamento da cobertura do solo de Irituia - PA com auxílio das informações orbitais dos projetos PRODES e TERRACLASS. In: Anais XVII Simpósio Brasileiro de Sensoriamento Remoto - SBSR, João Pessoa-PB, Brasil, 25 a 29 de abril, INPE.

ARAÚJO, C. M. de.; MORETTO NETO, L.; SCHMITT, V. G. H. (2008). O processo de gestão da marca "Vinho do porto": relevância da Marca-País e dos aglomerados produtivos. Revista de Ciências da Administração, v. 10, n. 20, p. 184-196, jan./abr.

CAÑETE, V. R. Os colonos de Nova Redenção: estratégias de permanência e dinâmica do campo da Região Guajarina do Estado do Pará. 2005. Tese (Doutorado em Geografia) -Núcleo de Altos Estudos Amazônicos, Universidade Federal do Pará, Belém

CARVALHO JÚNIOR, L. C.; HAUFFE, P. (2013) Motivações para a certificação na produção de alimentos orgânicos no estado de Santa Catarina. Revista Cadernos de Economia, Chapecó, v. 17, n. 32, p. 40 -51, jan. /jun.

CECHINEL, A. et al. (2016). Estudo/análise documental: uma revisão teórica e metodológica. UNESC, Criciúma, v. $5, \mathrm{n}^{\circ} 1$, janeiro/junho.

CIELO, I. D.; WENNINGKAMP, K. R.; SCHMIDT, C. M. (2014). A Participação Feminina no Agronegócio: O Caso da Coopavel - Cooperativa Agroindustrial de Cascavel. Revista Capital Científico Eletrônica (RCCe) - ISSN 2177-4153 - Vol. 12 n.1 - janeiro/março.

COSTA, F. de A. (1997). O açaí nos padrões de reprodução de camponeses agrícolas do nordeste paraense: os casos de Capitão Poço e Irituia. Paper do NAEA 076, abril.

FACIONI, D.; PEREIRA, M. W. G. (2015). Análise dos determinantes da sucessão em assentamento rural no estado de Mato Grosso do Sul. Organizações Rurais \& Agroindustriais, Lavras, v. 17, n. 1, p. 119-136.

FAPESPA - Fundação Amazônia de Amparo a Estudos e Pesquisas. (2016). Estatísticas Municipais Paraenses: Irituia. Diretoria de Estatística e de Tecnologia e Gestão da Informação. n. 1, jul./dez. Belém.

FIGARI, A. K. P.; BIALOSKORSKI NETO, S. (2015). Agregação de valor e distribuição de riqueza aos agricultores rurais: o caso de uma cooperativa de cafeicultores. RGC, Santa Maria, v.2, n.4, Págs. 99-114, jul./dez.

FRANK, L. et al. (2014). Alternativas de agregação de valor para a produção familiar: Cooperativa Amperence dos Agricultores de Vinho (Coopevi). COLÓQUIO - Revista do Desenvolvimento Regional Faccat - Taquara/RS - v. 11, n. 2, jul./dez.

GIL, A. C. Métodos e Técnicas de Pesquisa Social. 5 ed. São Paulo: Atlas, 2007.

GOMES, D.; GUIMARÃES, J.; PORRO, R. (2017). Acesso à ATER e os principais problemas técnicos enfrentados pela agricultura familiar no Nordeste Paraense. In: II Congresso Internacional de Ciências Agrárias. COINTER, PDVAgro. 
GOMES, L. de S.; BEZERRA, J. A. B. (2019) Alimentação escolar e desenvolvimento social local: o caso da aquisição de gêneros da agricultura familiar. Educação \& Formação, Fortaleza, v.4, n.11, p. 97-116, maio/ago.

HESPANHOL, R. A. de M. (2013). Programa de aquisição de alimentos: limites e potencialidades de políticas de segurança alimentar para a agricultura familiar. Soc. \& Nat., Uberlândia, 25 (3): 469-483, set/dez.

HOMMA, A. K.O. et al. (2013). Etnocultivo do jambu para abastecimento da cidade de Belém, estado do Pará. Amazônia: Ci. \& Desenv., Belém, v. 6, n. 12, jan./jun.

HURTIENNE, T. (1999) Agricultura Familiar na Amazônia Oriental: Uma comparação dos resultados da pesquisa socioeconômica sobre fronteiras agrárias sob condições históricas e agroecológicas diversas. Novos Cadernos NAEA, vol. $2, \mathrm{n}^{\circ} 1$ - dezembro.

IBGE - INSTITUTO BRASILEIRO DE GEOGRAFIA E ESTATÍSTICA. 2016. Disponível em: https://cidades.ibge.gov.br/brasil/pa/irituia/pesquisa/38/46996?indicador=47006. Acesso em 05/06/2019.

INCRA - INSTITUTO NACIONAL DE COLONIZAÇÃO E REFORMA AGRÁRIA. Tabela com módulo fiscal dos municípios. Disponível em: < http://www.incra.gov.br/tabela-modulo-fiscal >. Acesso em 18 de maio de 2019.

ILRI - International Livestock Research Institute. (1995). Livestock Policy Analysis. ILRI Training Manual 2. ILRI, Nairobi, Kenya. pp. 264. ISBN 92-9146-003-6.

LIMA, L. P. et al. (2013) Ocorrências e usos do Tucumã (Astrocaryum vulgare mart.) em comunidades ribeirinhas, quilombolas e de agricultores tradicionais no município de Irituia, Pará. Amazôn., Rev. Antropol. (Online) 5 (3) Especial: 762-778.

KATO, O. R.; SHIMIZU, M. K.; BORGES, A. C. M. R. B.; AZEVEDO, C. M. B. C. de.; OLIVEIRA, J. S. R. de.; VASCONCELOS, S. S.; SÁ, T. D. de A. (2012). Desenvolvimento da produção de frutas em sistemas agroflorestais no estado do Pará. In: XXII Congresso Brasileiro de Fruticultura, Bento Gonçalves.

MERINO, E.; MERINO, G., FIGUEIREDO, L. F.G. (2007). Design: Valorizando produtos da agricultura familiar - Hermes de Ré. Florianópolis: EPAGRI, 109p.

MIRANDA, S. B. Contribuição de Quintais Agroflorestais para a Segurança Alimentar de Agricultores Familiares no Baixo Irituia, Nordeste Paraense. 2011. 104 f. Dissertação (Mestrado em Agriculturas Familiares e Desenvolvimento Sustentável), Universidade Federal do Pará, Núcleo de Ciências Agrárias e Desenvolvimento Rural, Belém, 2011.

MIRANDA, S.; KATO, O. R; SABLAYROLLES, M. G. (2013). Caracterização e importância dos quintais agroflorestais aos agricultores familiares do Baixo Irituia, Pará. Cadernos de Agroecologia - ISSN 22367934 - Vol 8, No. 2, Nov.

MORAES, M. D. de.; SANT’ANA, A. L. (2015). Características Socioeconômicas do Assentamento Banco da Terra, Nova Xavantina (MT): uma análise sob a ótica da adoção ou construção de conhecimentos. Rev. Econ. Sociol. Rural. vol.53 no.4 Brasília Out./Dez.

MORAES, M. H. C. da S. Agrobiodiversidade dos quintais e socioeconomia dos agroecossistemas familiares da Cooperativa D'Irituia, Pará, Brasil. 2017. 189 f. Dissertação (Mestrado em Ciências Florestais), Universidade Federal Rural da Amazônia, Programa de Pós-Graduação em Ciências Florestais, Belém, 2017.

MORÉ, C. L.O. O. (2015). A "entrevista em profundidade" ou "semiestruturada", no contexto da saúde: Dilemas epistemológicos e desafios de sua construção e aplicação. Atas - Investigação Qualitativa nas Ciências Sociais, v. 3, CIAIQ.

MOREIRA, J. G.; BECKER, C. (2018). Implantação de um sistema participativo de certificação orgânica pelos assentados da reforma agrária: o caso do OCS Cerro dos Munhoz em Santana do Livramento (RS). ACTA Geográfica, Boa Vista, v.12, n.28, jan./abr. Pp. 1-16.

OLIVEIRA, J.S.R. de. Uso do território, Experiências Inovadoras e Sustentabilidade: um estudo em unidades de produção familiares de agricultores na área de abrangência do programa PROAMBIENTE, Nordeste Paraense. 2006. 131f. Dissertação (Mestrado em agriculturas familiares e desenvolvimento sustentável), Universidade Federal do Pará, Centro de Ciências Agrárias, Núcleo de Estudos em Agricultura Familiar, Belém, 2006. 
OLIVEIRA, D.; SCHNEIDER, S. (2009). O Futuro das Unidades Familiares: Uma Análise das Possibilidades de Sucessão Hereditária entre os Agricultores Ecologistas de Ipê/RS. Rev. Bras. de Agroecologia/nov. Vol. 4 n 2.

PADOVAN, M. P.; GOMES, J. B. P.; PADOVAN, D. S. da S. (2017). Produção orgânica no âmbito da agricultura familiar em Mato Grosso do Sul. Redes - Santa Cruz do Sul: Universidade de Santa Cruz do Sul, v. 22, n. 3, setembro-dezembro.

POMPEU, D. do S. do S. et al. (2009). Sistemas Agroflorestais comerciais em áreas de agricultores familiares no município de Bragança, Pará: estudo de caso. Rev. ciências agrárias, Belém, n. 51, p.191-210, jan./jun.

RAMBO, J. R. Produzir e vender? O caso do programa de aquisição de alimentos de agricultores familiares assentados da reforma agrária em Tangará da Serra-MT. 2016.182 p. Tese (Doutorado em Agronomia), Universidade Estadual Paulista "Júlio de Mesquita Filho", Faculdade de Engenharia Campus de Ilha Solteira, MT, 2016.

REGO, A. K. C.; KATO, O. R. (2017). Agricultura de corte e queima e alternativas agroecológicas na Amazônia. Novos Cadernos NAEA, v. 20, n. 3, p. 203-224, set-dez.

ROSA, L. A. B. da; TSAY, C. C. J.; RODRIGUES, F. S. C. (2010). Cooperativa de Crédito Rural: Análise do Perfil dos Cooperados. UNOPAR Cient., Ciênc. Juríd. Empres., Londrina, v. 11, n. 1, p. 75-80, Mar.

SILVA, C. T. B. da; et al. (2015). Sistemas Produtivos dos Agricultores Filiados à Cooperativa Agropecuária dos Agricultores Familiares Irituienses - Irituia-PA. Cadernos de Agroecologia - ISSN 2236-7934 - Vol $10, \mathrm{~N}^{\mathrm{o}} 3$.

SOUSA, R. B. de; MACEDO, C.O. (2011). Comunidades camponesas no Nordeste Paraense: o caso de São Judas e Cravo. Revista Geografia (Londrina), v. 20, n. 2, p. 115-128, maio/ago.

SOUSA, F. F. de; PIRAUX, M. (2015). A construção social da qualidade da farinha de mandioca em comunidades rurais na Amazônia paraense. Novos Cadernos NAEA; v. 18 n. 3; p. 199-222, set-dez.

SOUZA, P. S. C. de; et al. (2017). Dimensões da sustentabilidade: o processo de certificação "fair trade" em cooperativa no Marajó, Pará. P2P \& INOVAÇÃO, Rio de Janeiro, v. 3 n. 2, p.177-196, Mar./ set.

SOUZA, M. L. M. de.; SOBRINHO, M. V. (2011) Cooperativismo e economia solidária: uma análise do ambiente político-institucional e do desempenho de organizações cooperativas na Amazônia Paraense. Revista Movendo Ideias; Vol. 18 n. 1 jan. a jun.

TARGANSKI, H.; SILVA, N. L. S da.; BRITO, M. M. de. (2017). Análise de indicadores sociais em sistemas de produção agropecuários do tipo familiar. Gestão e Desenvolvimento; Novo Hamburgo. v. 14. n. 1. jan./jun.

VALENT, J.C.; et al. (2014). Qualidade de produtos orgânicos: a percepção dos agricultores de hortaliças de uma feira ecológica em Porto Alegre - RS. REGET - V. 18 n. 1 Set-Dez., p. 1072-1082.

VERGARA, S. C. Projetos e relatórios de pesquisa em administração. 5. ed. São Paulo: Atlas, 2004.

VOLPATO, M. M. L.; et al. (2016). Cadastro Ambiental Rural para a agricultura familiar. EPAMIG. Circular Técnica, n.238, abr.

WAGNER, S. A.; et al. Gestão e planejamento de unidades de produção agrícola. Porto Alegre: Editora da UFRGS, 2010. $128 \quad$ p. a $^{\mathrm{a}}$ edição: 2010.2 Disponível http://www.ufrgs.br/cursopgdr/downloadsSerie/derad015.pdf. Acesso em 12/08/2018. 